\title{
Seemingly Unrelated Interventions: Environmental Management Systems in the Workplace and Energy Saving Practices at Home
}

\author{
Toshi H. Arimura ${ }^{1,2}$ D $\cdot$ Kazuyuki Iwata ${ }^{3} \cdot$ Hajime Katayama $^{4} \cdot$ Mari Sakudo $^{5}$
}

Accepted: 2 October 2021 / Published online: 18 October 2021

(c) The Author(s) 2021

\begin{abstract}
To reduce their environmental impacts, a growing number of organizations worldwide have implemented environmental management systems (EMSs). In these organizations, energy conservation activities become usual behaviors for employees; thus, we hypothesize that employees continue such energy saving behaviors at home. This hypothesis is supported by data from surveys of individuals in Japan. Specifically, we find that the probability of engaging in energy saving practices at home is higher and that expenditures on electricity use are lower for individuals who work in organizations that implement EMSs than for individuals who do not work in organizations with EMSs. Our results suggest that beyond the original purpose of helping organizations reduce their environmental impacts, EMSs work as an intervention to promote household energy saving.
\end{abstract}

Keywords Energy saving practices $\cdot$ Electricity $\cdot$ Environmental management system · ISO14001 $\cdot$ Energy efficiency $\cdot$ Household electricity expenditure

Toshi H. Arimura

toshi.arimura@gmail.com

Kazuyuki Iwata

iwata.kazuyu@gmail.com

Hajime Katayama

hajime.katayama@waseda.jp

Mari Sakudo

sakudo@sk.tsukuba.ac.jp

1 Faculty of Political Science and Economics, Waseda University, 1-6-1 Nishiwaseda, Shinjuku-ku, Tokyo 169-8050, Japan

2 Research Institute for Environmental Economics and Management, Waseda University, Tokyo, Japan

3 Faculty of Economics, Matsuyama University, 4-2, Bunkyo-cho, Matsuyama, Ehime 790-8578, Japan

4 Faculty of Commerce, Waseda University, 1-6-1 Nishiwaseda, Shinjuku-ku, Tokyo 169-8050, Japan

5 Faculty of Engineering, Information and Systems, University of Tsukuba, Tennodai 1-1-1, Tsukuba, Ibaraki 305-8573, Japan 
JEL Classification Q40 - Q50

\section{Introduction}

Global warming is among the most serious problems that our society needs to address. The average global temperature has increased by approximately $1.4{ }^{\circ} \mathrm{F}\left(0.8{ }^{\circ} \mathrm{C}\right)$ since 1880 . With the current level of greenhouse gas (GHG) emissions, each successive decade is expected to become warmer than the previous one (Melillo et al. 2014). Reduction of GHG emissions is therefore an urgent need.

Similar to the business sector, households are responsible for a large part of GHG emissions. Households represent $15-20 \%$ of primary energy use in developed countries and a higher share in developing countries (Dzioubinski and Chipman 1999). Thus, households represent an important target group for interventions (Abrahamse et al. 2005), motivating many researchers mostly in the fields of social and environmental psychology to investigate how to promote energy saving among households. For an excellent review, see the study by Abrahamse et al. (2005).

This study examines environmental management systems (EMSs) as a potential intervention to promote household energy saving. This idea may sound odd to those who are familiar with EMSs because the original purpose of EMSs is not to influence household energy saving but to help organizations, such as companies, associations, and governmental agencies, reduce the environmental impacts generated by their products, services or activities. Therefore, even organizations that currently implement EMSs are unlikely to be aware of their potential role in promoting household energy saving. We will point out, however, that EMSs may influence household energy saving, although EMSs and the energy consumption of households may be seemingly unrelated.

An EMS is a formal set of processes and procedures that defines how an organization manages its potential impacts on the environment. Implementation of a typical EMS requires setting an environmental principle and a plan ("Plan"), establishing a quantifiable target to reduce the organization's environmental impacts ("Do"), and monitoring of its environmental progress ("Check"). The management revisits the principle and plan and later sets a new target in a revised plan ("Act"). This repetitive cycle is known as "PDCA" (Plan-Do-Check-Act) (Coglianese and Nash 2001). The increased control is expected to result in continuous improvement in the environmental performance of the organization (the United States Environmental Protection Agency 2014).

To manage environmental issues systematically, a growing number of organizations have implemented EMSs. The most commonly used framework for an EMS is ISO 14001, the international standard established in 1996 by the International Organization for Standardization (ISO). At least 346,147 organizations in 201 countries had been certified to ISO 14001 by the end of 2016, compared to 14,106 in 84 countries by 1999 (ISO 2003, 2016). Likewise, 3865 organizations and 9140 sites were registered under Eco-Management Audit Schemes (EMAS) as of October 2017 (European Commission 2017). EMS implementation may be even more prevalent than implied by these figures due to the presence of organizations that implement EMSs without being certified/registered under ISO 14001 or EMAS (i.e., informal EMSs or organization-specific EMSs).

Motivated by a rapid increase in the prevalence of EMSs, a number of studies have investigated the potential environmental benefits of EMS implementation, including the reduction in environmental impacts (e.g., Arimura et al. 2008; Brouwer and van Koppen 
2008; Daddi et al. 2011; Iraldo et al. 2009; Potoski and Prakash 2005), compliance with environmental regulations (e.g., Dahlström et al. 2003; Dasgupta et al. 2000) and technological environmental innovations (e.g., Lim and Prakash 2014; Rennings et al. 2006; Wagner 2007, 2008). The results are not necessarily in agreement, depending on how environmental performance is measured.

This study departs from the literature by addressing an unexplored aspect of EMSs. The point of departure is the consideration of how employees are affected by the introduction of EMSs. When an organization introduces an EMS, its objectives often include a reduction in electricity use. Therefore, employees are encouraged to engage in energy saving activities, such as turning off lights or personal computers when not in use, to a greater extent than before. In addition, the results of these practices are periodically assessed. The employees' involvement in this process may render energy saving behaviors a usual act that does not require much effort. Therefore, it may not be surprising if employees continue to engage in energy saving behaviors at home.

This argument is supported by survey data of individuals in Japan. Specifically, our results show that the probability of engaging in energy saving practices at home is higher and also that the expenditures on electricity use are lower when individuals' workplaces implement EMSs than when their workplaces do not. These results suggest that beyond the original purpose of helping organizations reduce the environmental impacts generated by their activities, EMSs have previously unnoticed positive effects on household energy saving.

\section{Background}

\subsection{Environmental Management Systems}

EMSs require organizations, in either the private or public sectors, to "establish programs, systems and structures for their internal operation regarding the environment" (Prakash and Potoski 2006). In doing so, organizations with EMSs often provide training and education, such as general awareness training (Zutshi and Sohal 2004), to promote environmental conservation within the organization. Zutshi and Sohal (2004) claim that general awareness training should include the topic of the impact of operations and individuals' actions on the environment. Through this training, employees can learn how to mitigate the environmental impact of their daily operations.

Academic literature examines environmental training as a critical element of EMSs (e.g., Jabbour 2013). However, such literature does not document in detail the content of the training or education programs provided by organizations with EMSs. Therefore, in this subsection, we introduce specific examples of environmental training and promotion of environmental conservation behaviors in Japanese firms with EMSs.

We begin with an example of a consulting firm with ISO 14001, i.e., NS Solutions. This firm provides employees with environmental education every year to enhance their understanding of the importance of environmental conservation ${ }^{1}$. As is typical in organizations with ISO 14001 in Japan, the firm's environmental management objectives include a reduction in electricity usage. The firm implements environmental education or training to

1 https://www.nssol.nssmc.com/corporate/environmental.html (Accessed in April 2018). 
promote energy savings. Everyone in the firm, i.e., all individuals from the top managers to all staff, is encouraged to participate in the following energy saving practices: turning off lights in the workspace during lunch hours, turning off PCs when leaving the workplace, turning off lights in rooms that are not in use, and controlling the temperature settings of air conditioners by setting the temperature at $28{ }^{\circ} \mathrm{C}$ or higher in summer and $20{ }^{\circ} \mathrm{C}$ or lower in winter, as advocated in the campaign by the Japanese Ministry of the Environment (the Energy Conservation Center, Japan 2012).

Another example of a firm with an EMS is a transport company, i.e., Geneq, that evaluates electricity usage every month using graphs such that the usage is visible and noticed. ${ }^{2}$ Employees are provided with education as well as with notebooks that explain the company's environmental policy, the targets, the employee's obligations, and energy saving practices to engage in. Comprehension tests are regularly conducted. Some organizations further encourage workers to voluntarily participate in environmental conservation activities outside the workplace to promote their environmental awareness.

Organizations in the public sector engage in similar activities to promote environmental conservation through employees' behavioral changes. For example, the local government of Kanagawa, which is a prefecture next to Tokyo, has adopted an environmental management system. ${ }^{3}$ As a part of the environmental training program, the Environmental Planning Division of the Kanagawa prefectural government provides DVDs to other departments to allow employees to learn about the current status of climate change issues/policy or water conservation. Moreover, the division uses posters to encourage employees to practice environmental conservation behaviors, such as "turn off lights when unnecessary" in the workplace. ${ }^{4}$

As shown in these cases, Japanese organizations with EMSs provide environmental education to employees. Such education often focuses on energy and climate issues. Furthermore, these organizations encourage employees to adopt the energy saving practices mentioned above.

\subsection{Previous Literature on EMSs}

A number of previous studies have found that EMS implementation results in better environmental performance. ${ }^{5}$ For example, Russo (2002) provided evidence that ISO 14001 certification helped U.S. electronics facilities reduce their toxic emissions. Potoski and Prakash (2005) found that ISO 14001 adoption results in decreased air pollutant emissions. Similarly, Iraldo et al. (2009) found that EMAS has a positive effect on the level of selfreported environmental performance perceived by the organization itself.

\footnotetext{
${ }^{2}$ http://www.geneq.co.jp/corporate/environment.html (Accessed in April 2018).

3 http://www.pref.kanagawa.jp/cnt/f534419/p1016428.html (Accessed in April 2018).

4 http://www.pref.kanagawa.jp/uploaded/attachment/818148.pdf (Accessed in April 2018).

5 Previous studies used various methods to examine the impact of EMS. For example, binary probit (Rennings et al. 2006; Iraldo et al. 2009), multivariate regression (Iraldo et al. 2009) were used, in addition to the analyses of EMS related statistics (Dahlström et al. 2003; Tan 2005) and meta analyses (Darnall and Sides 2008). To take into account potential endogeneity of EMSs, some studies employed bivariate probit and multinomial logit (Wagner 2008), two stage least squares (Dasgupta et al. 2000), and linear regression with endogenous treatment effect (Potoski and Prakash 2005). For longitudinal data, panel fixed effects and instrumental variables (Barla 2007; Nishitani 2011; Lim and Prakash 2014), fixed effects GMM and sample selection corrections methods (Lim and Prakash 2014) were applied.
} 
Similar results are obtained when technological environmental innovations are used as a specific measure for environmental performance. For example, Rennings et al. (2006) found that the maturity of an EMS has a positive influence on environmental process innovations among German EMAS-validated facilities. Likewise, Wagner (2007) examined German manufacturing firms and provided evidence that the implementation level of an EMS has a positive effect on environmental process innovation. Wagner (2008) also observed this pattern among firms in nine European countries. Lim and Prakash (2014) found that country-level ISO participation is a strong predictor of a country's environmental patent applications.

On the other hand, some studies have found little evidence that EMSs improve organizations' environmental performance. For example, Barla (2007) examined 37 plants in Quebec's pulp and paper industry and found that ISO 14001 does not result in a reduction in total suspended solid emissions. Using U.K. data, Dahlström et al. (2003) showed that neither ISO 14001 nor EMAS had a positive effect on compliance with environmental regulations, contrary to evidence found by Dasgupta et al. (2000) for facilities in Mexico. According to Darnall and Sides (2008), who conducted a meta-analysis, the evidence is inconclusive on whether adherence to ISO 14001 results in improved environmental performance.

In addition to improved environmental performance, a wide variety of potential benefits from EMSs have been listed and examined in the literature, including profitability, market expansion, competitive products/services, efficiency, an improved company image, improvement in customer satisfaction and improved relations with stakeholders (e.g., Nishitani 2011; Tan 2005; Tari et al. 2012).

As shown in the literature review, EMSs have been extensively examined in the context of organizational performance. In contrast, less attention has been paid to whether EMS implementation influences employees within the organization. According to a few studies, employee morale seems to change as a result of EMS implementation. For example, Hillary et al. (1998) found that one benefit perceived by registered EMAS sites is improved employee morale. According to Pan (2003), firms in Japan and Taiwan tend to perceive improved employee morale as one of the benefits from ISO 14001. Poksinska et al. (2003) provided similar evidence after examining Swedish firms that are certified to ISO 14001.

Several studies have also shown that employees become more environmentally aware when their workplaces implement EMSs. For example, Rondinelli and Vastag (2000) conducted an in-depth case study of a plant in South Carolina and found that the plant managers viewed one of the benefits of ISO 14001 to be its influence on employee environmental awareness. Schylander and Martinuzzi (2007) examined Austrian firms and observed that one significant contribution of ISO 14001 is raising employee awareness of environmental issues; $85 \%$ of the firms in the survey perceived middle, strong or very strong improvements.

\subsection{Relationship Between EMSs in the Workplace and Household Energy Saving}

This study extends the scope of previous research by shedding light on an overlooked aspect of EMSs. In particular, we argue that EMS implementation functions as an intervention promoting household energy saving even though EMSs and household energy saving may seem to be unrelated. The idea is that an EMS induces employees to behave in a more energy-conserving way at home. To understand this idea, consider an organization that introduces an EMS. The management initially sets a target, such as a $2 \%$ reduction 
in electricity consumption during a certain period, to encourage energy saving behaviors among the employees. The person in charge regularly monitors the extent to which the employees engage in energy saving activities, such as turning off lights when not in use, and keeps the employees aware of the target. The employees also receive environmental education, which is an essential element of an EMS. At the end of the period, electricity consumption is compared with the target, and the report is shared with the employees. This allows the employees to associate the amount of reduction achieved through their behaviors. Then, the management sets a new target for the employees, further encouraging their energy saving behaviors. Through this cycle, the employees may not only better understand the significance of energy saving behaviors but also become accustomed to engaging in energy saving behaviors in the workplace. Finally, the employees may consciously or unconsciously transfer this knowledge and habit to their homes.

This argument, except for the final part (i.e., transferring the knowledge and habit to their home), is consistent with the evidence provided by Arimura et al. (2008). Using data of facilities in Japan, these authors found that an ISO 14001 certification is associated with reduced natural resource use. This evidence can be interpreted as suggestive that when an EMS is implemented, employees behave in a more energy-conserving way in the workplace. This argument is also supported by a field experimental study by Siero et al. (1989). These authors developed a behavioral program to change the driving behavior of mail van drivers. Similarly to an EMS, the program was designed to provide drivers information, task assignment, and feedback regarding gasoline consumption. The program was implemented in the Netherlands Postal and Telecommunication Services and resulted in energy savings of $7.3 \%$.

Several psychological ideas may also support our proposed mechanism. First, the mechanism can be viewed as the internationalization of norms, and once norms are internalized, certain behaviors become "instinctive" (Gavrilets and Richerson 2017). In our context, this view suggests that individuals internalize the importance of energy saving through workplace activities, thereby instinctively engaging in energy saving behaviors at home. Second, the concept of (stimulus) generalization may also explain such behavior (Dollinger et al. 1984). According to this idea, individuals engage in the same behaviors without changing their norms. Finally, the mechanism may be viewed as spillovers of behaviors (Thøgersen and Ölander 2003). According to this view, energy saving behaviors at home can be considered spillovers of behaviors at the workplace.

Based on these arguments, we conclude this section with the following two testable hypotheses: (1) the probability of engaging in energy saving practices at home is higher and (2) household expenditures on electricity use are lower, for individuals who work in organizations that implement EMSs than those who do not work in organizations with EMSs.

\section{Do EMSs in the Workplace Induce Energy saving Activities at Home?}

\subsection{Data}

To address the first question, we use data derived from an online survey conducted in February 2016. The target subjects are aged 20 years or older and reside in Japan. In total, 2618 individuals recruited among 1,350,000 survey monitors registered with Market Development Research, which is a marketing research company in Tokyo, participated in 
the survey. We requested the company to broadly divide the country into six regions and collect subjects in such a way that the density of the respondents in each region is approximately equal to the corresponding density in the Population Census in Japan and that the distributions of age and gender in each region are matched with those in the Census. We decided to apply this adjustment because we were concerned about a possible correlation between internet accessibility and residential locations; people in urban areas may be more likely to participate in an online survey than those in rural areas. After excluding non-working respondents, such as students and homemakers, and those with incomplete answers, the sample size was reduced to 1723 . Table 1 presents the descriptive statistics.

\subsubsection{Dependent Variables}

We consider four energy saving practices recommended by the Energy Conservation Center, Japan (2012), which provides an official guideline for promoting household energy saving. Two dependent variables are related to air conditioners and are constructed from the following survey items: (w)hen you are in a living room at home, (1) "do you set the air conditioner temperature at $28{ }^{\circ} \mathrm{C}$ or higher in summer?" ( $\left.e s p_{1}\right)$ and (2) "do you set the air conditioner temperature at $20{ }^{\circ} \mathrm{C}$ or lower in winter?" $\left(e s p_{2}\right)$. The other two variables are constructed from the following items: (w)hen you are in a living room alone and then leave the room for 5 min or more, (3) "do you turn off the TV(s)?" (esp $\left.p_{3}\right)$ and (4) "do you turn off the light(s)?" $\left(e s p_{4}\right)$. The respondents were asked to answer each question by choosing from the following four ordered categories: "never" (coded as 1), "rarely" (coded as 2), "occasionally" (coded as 3), and "fairly often" (coded as 4). Notably, some respondents do not use standard air conditioners during the winter; instead, these respondents use traditional Japanese-style stoves that are not equipped with temperature settings. In addition, a proportion of the respondents do not possess televisions. As a result, the number of observations differs across the practices; specifically, there are 1435 observations of air conditioner use during the summer, 923 observations of air conditioner use during the winter, 1641 observations of TV use, and 1723 observations of light use.

The distribution of the replies for each practice is shown in Fig. 1. For each practice, respondents who answered "fairly often" occupy the largest share. For air conditioner practices, respondents are found to be engaged relatively more in summer than in winter.

\subsubsection{Explanatory Variables}

To measure EMS implementation in the respondents' workplaces, we use the following survey item: "(h)as the organization that you work for implemented an environment management system (for example, ISO 14001, Eco-Action 21, etc.)?"6 The respondents were asked to choose from "yes," "no," or "don't know," and 18\% of the respondents replied "yes," 39\% of the respondents replied "no," and the remaining respondents replied "do not know." For our analysis, we construct two dummy variables: ems, which equals one if the respondent chose "yes", and $e m s_{d k}$, which equals one if the respondent chose "don't know." We initially include $e m s$, but not $e m s_{d k}$, in the models; thus, we treat "no" and "don't know" equally. This modeling approach assumes that when an EMS is adopted, employees

\footnotetext{
6 The Eco-Action 21 is a formal certification for Japanese small and medium-scale organizations. The certification is provided by the Institute for Promoting Sustainable Societies.
} 
Table 1 Descriptive statistics

\begin{tabular}{|c|c|c|c|c|c|}
\hline Variable & Obs & Mean & SD & Min & $\operatorname{Max}$ \\
\hline$e s p_{1}$ : Set to 28 degrees in summer & 1435 & 2.95 & 1.09 & 1 & 4 \\
\hline$e s p_{2}:$ Set to 20 degrees in winter & 923 & 2.66 & 1.15 & 1 & 4 \\
\hline$e p_{3}:$ Turn TV off when unnecessary & 1641 & 2.87 & 1.14 & 1 & 4 \\
\hline$e s p_{4}$ : Turn light off when unnecessary & 1723 & 2.81 & 1.13 & 1 & 4 \\
\hline ems & 1723 & 0.18 & 0.38 & 0 & 1 \\
\hline ems_dk: Don't know whether EMS is adopted & 1723 & 0.43 & 0.49 & 0 & 1 \\
\hline Comfortable temperature in summer & 1435 & 25.94 & 2.08 & 16 & 30 \\
\hline Comfortable temperature in winter & 923 & 22.80 & 2.82 & 15 & 30 \\
\hline Area-average temperature in January 2016 & 1723 & 4.84 & 3.05 & -9.68 & 19.66 \\
\hline Male & 1723 & 0.60 & 0.49 & 0 & 1 \\
\hline Age & 1723 & 43.61 & 12.30 & 20 & 69 \\
\hline Married & 1723 & 0.48 & 0.50 & 0 & 1 \\
\hline Employed regularly & 1723 & 0.53 & 0.50 & 0 & 1 \\
\hline Number of family members & 1723 & 2.81 & 1.32 & 1 & 9 \\
\hline \multicolumn{6}{|l|}{ House type } \\
\hline Owned house & 1723 & 0.65 & 0.48 & 0 & 1 \\
\hline Detached house & 1723 & 0.56 & 0.50 & 0 & 1 \\
\hline \multicolumn{6}{|l|}{ TV type } \\
\hline Liquid crystal & 1641 & 0.89 & 0.31 & 0 & 1 \\
\hline Plasma & 1641 & 0.08 & 0.27 & 0 & 1 \\
\hline Others & 1641 & 0.03 & 0.16 & 0 & 1 \\
\hline \multicolumn{6}{|l|}{ Household income } \\
\hline Less than 2 million yen & 1723 & 0.08 & 0.28 & 0 & 1 \\
\hline Between 2 million yen and 3 million yen & 1723 & 0.11 & 0.31 & 0 & 1 \\
\hline Between 3 million yen and 4 million yen & 1723 & 0.15 & 0.36 & 0 & 1 \\
\hline Between 4 million yen and 5 million yen & 1723 & 0.15 & 0.36 & 0 & 1 \\
\hline Between 5 million yen and 7 million yen & 1723 & 0.19 & 0.39 & 0 & 1 \\
\hline Between 7 million yen and 10 million yen & 1723 & 0.20 & 0.40 & 0 & 1 \\
\hline Between 10 million yen and 15 million yen & 1723 & 0.09 & 0.28 & 0 & 1 \\
\hline More than 15 million yen & 1723 & 0.03 & 0.16 & 0 & 1 \\
\hline \multicolumn{6}{|l|}{ Educational status } \\
\hline Junior high school & 1723 & 0.02 & 0.14 & 0 & 1 \\
\hline High school & 1723 & 0.26 & 0.44 & 0 & 1 \\
\hline Higher professional school & 1723 & 0.07 & 0.25 & 0 & 1 \\
\hline Junior college & 1723 & 0.11 & 0.31 & 0 & 1 \\
\hline University & 1723 & 0.46 & 0.50 & 0 & 1 \\
\hline Graduate school & 1723 & 0.06 & 0.23 & 0 & 1 \\
\hline Others & 1723 & 0.03 & 0.17 & 0 & 1 \\
\hline \multicolumn{6}{|l|}{ Occupational type } \\
\hline Specialist & 1723 & 0.25 & 0.43 & 0 & 1 \\
\hline Administration & 1723 & 0.06 & 0.24 & 0 & 1 \\
\hline Desk work & 1723 & 0.27 & 0.44 & 0 & 1 \\
\hline Sales & 1723 & 0.12 & 0.33 & 0 & 1 \\
\hline Service & 1723 & 0.13 & 0.34 & 0 & 1 \\
\hline
\end{tabular}


Table 1 (continued)

\begin{tabular}{lccccc}
\hline Variable & Obs & Mean & SD & Min & Max \\
\hline Production & 1723 & 0.13 & 0.33 & 0 & 1 \\
Maintenance & 1723 & 0.01 & 0.10 & 0 & 1 \\
Agriculture & 1723 & 0.01 & 0.10 & 0 & 1 \\
$\quad$ Transportation and communication & 1723 & 0.02 & 0.15 & 0 & 1 \\
Industry & & & & & \\
Agriculture and fishery & 1723 & 0.01 & 0.11 & 0 & 1 \\
Construction & 1723 & 0.06 & 0.23 & 0 & 1 \\
Manufacturing & 1723 & 0.17 & 0.37 & 0 & 1 \\
Energy & 1723 & 0.01 & 0.11 & 0 & 1 \\
Information and communication & 1723 & 0.08 & 0.26 & 0 & 1 \\
Transportation & 1723 & 0.03 & 0.18 & 0 & 1 \\
Wholesale, retail, and restaurant & 1723 & 0.14 & 0.34 & 0 & 1 \\
Finance, insurance, and estate & 1723 & 0.06 & 0.23 & 0 & 1 \\
Service & 1723 & 0.38 & 0.48 & 0 & 1 \\
Public & 1723 & 0.07 & 0.26 & 0 & 1 \\
\hline
\end{tabular}

(a)

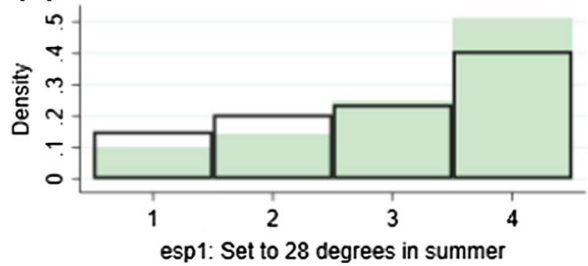

(c)

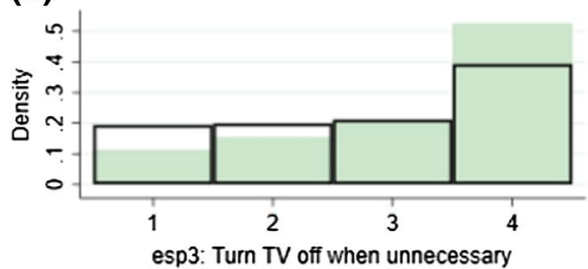

(e)

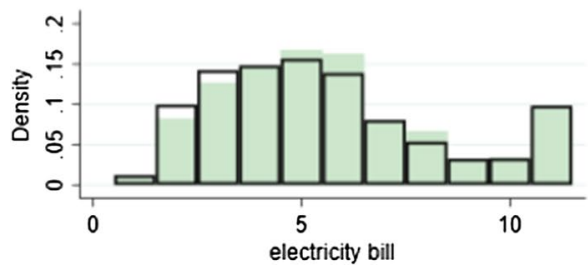

(b)

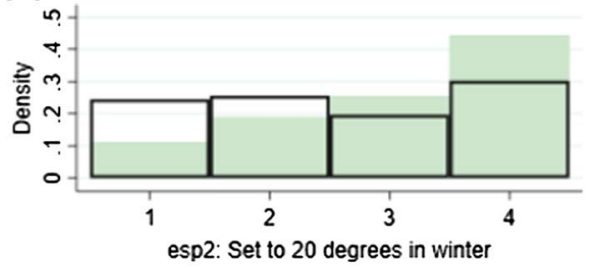

(d)

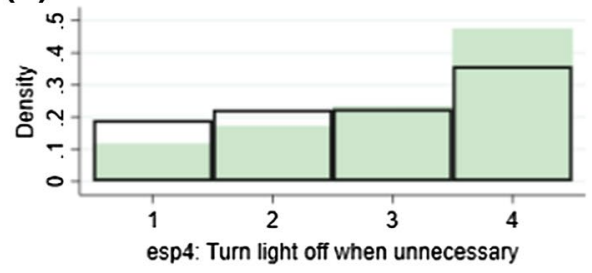

Fig. 1 Distributions of energy saving practices and electricity bills 
Table 2 Mean-comparison tests

\begin{tabular}{|c|c|c|c|c|c|}
\hline & \multicolumn{2}{|c|}{$e m s=0$} & \multicolumn{2}{|c|}{$e m s=1$} & \multirow[t]{2}{*}{$t$-value } \\
\hline & Obs & Mean & Obs & Mean & \\
\hline$e s p_{1}:$ Set to 28 degrees in summer & 1161 & 2.90 & 274 & 3.17 & $-3.96 * * *$ \\
\hline$e s p_{2}:$ Set to 20 degrees in winter & 727 & 2.56 & 196 & 3.03 & $-5.51 * * *$ \\
\hline$e s p_{3}$ : Turn TV off when unnecessary & 1342 & 2.80 & 299 & 3.14 & $-4.93 * * *$ \\
\hline$e s p_{4}:$ Turn light off when unnecessary & 1416 & 2.75 & 307 & 3.07 & $-4.69 * * *$ \\
\hline
\end{tabular}

$* * *, * *$, and $*$ correspond to the 1,5 and $10 \%$ levels of significance, respectively

are aware of the EMS. This assumption does not seem to be unreasonable as a component of an EMS is ensuring that all employees are involved in and committed to the EMS (The Commonwealth of Australia 2017). For the robustness checks, we examine models that include both ems and $e m s \_d k$, thereby allowing for the possibility that "no" and "don't know" have differential effects. The results are presented in Appendix, revealing that our main findings are not considerably affected by the inclusion of $e m s \_d k$.

In addition to EMSs, sociodemographic and household factors may influence energy saving behaviors. To control for individuals' sociodemographic characteristics, our models include age, a dummy variable for being a male, a dummy variable for being a regular employee, dummy variables for education, dummy variables for occupation, and dummy variables for the industry in which the respondent works. In addition, the models incorporate two variables that represent the temperatures at which the respondents feel comfortable in summer and winter. For household and house-related factors, the models include the number of household members, a dummy for homeownership, a dummy for living in a detached house, dummy variables for household income, and dummy variables for TV types. Finally, to control for regional differences, the models include the monthly average of the mean daily temperature in the seat of the prefectural government in January 2016 as reported by the Japan Meteorological Agency.

As will be discussed later, we control for the endogeneity of the EMSs. For this purpose, the number of employees in the organization the respondent works for is used as an instrumental variable. To obtain the variable, we used a survey question in which the respondents were asked to choose from the following alternatives: "not more than 10," "from 11 to 50," "from 51 to 100," "from 101 to 500," "from 501 to 1000," "from 1001 to 3000 ," "from 3001 to 5000 ," "from 5001 to 10,000 ," and " 10,001 or more."

\subsection{Comparison of Two Groups}

To examine the relationship between EMSs and energy saving practices, we first examine the empirical distributions of energy saving practices $\left(e s p_{j}, j=1, \ldots, 4\right)$ between two respondent groups by the EMS status of their workplaces ( $e m s=1$ and $e m s=0)$ in Fig. 1. The green and white bars represent the respondents for $e m s=1$ and $e m s=0$, respectively. According to the figures, the distributions seem to be different from each other. For all practices, we find larger densities at "fairly often" for $e m s=1$ than for $e m s=0$. Additionally, smaller densities are observed at "never" and "rarely" in the former group than in the latter group. 
We next check the mean differences of energy saving practices by group. Table 2 represents the results of the mean-comparison tests assuming normal distributions and allowing for unequal variances. It is found that the respondents who work for organizations with EMSs are more likely to be engaged in all energy saving practices at home than those who work for organizations without EMSs. In addition, according to non-parametric Kolmogorov-Smirnov tests, the distribution of each practice differs across the groups at the $1 \%$ level of significance. These differences are consistent with the idea that EMSs in workplaces induce employees to engage in energy saving practices at home.

\subsubsection{Model and Results}

We now examine whether the result in the previous section is an artifact of not controlling for individual observed characteristics. For this purpose, we estimate an ordered probit model to account for the ordered categorical nature of the dependent variable $\left(e s p_{j}\right)$; it takes one, two, three and four if the individual "never," "rarely," "occasionally," and "fairly often," engages in energy saving practice $j$, respectively.

The underlying unobserved propensity to engage in the practice $\left(e s p_{j}^{*}\right)$ is assumed to depend on whether the individual's workplace implements an EMS (ems), a set of other observed factors $(\boldsymbol{x})$, and a set of unobserved factors that consist in the error term $\left(u_{j}\right)$ :

$$
e s p_{j}^{*}=\alpha_{j} \cdot e m s+\boldsymbol{x} \boldsymbol{\beta}_{j}+u_{j},
$$

where $\left(\alpha_{j}, \boldsymbol{\beta}_{j}^{\prime}\right)$ are unknown parameters, $\boldsymbol{x}$ does not contain a constant, and $u_{j}$ is standard normally distributed. The observed categorical variable is assumed to connect with the unobserved propensity in the following manner:esp $p_{j}=1$ if $e s p_{j}^{*}<\mu_{1 j}, e s p_{j}=2$ if $\mu_{1 j} \leq e s p_{j}^{*}<\mu_{2 j}, e s p_{j}=3$ if $\mu_{2 j} \leq e s p_{j}^{*}<\mu_{3 j}$, and $e s p_{j}=4$ if $\mu_{3 j} \leq e s p_{j}^{*}$ where $\left(\mu_{1 j}, \mu_{2 j}, \mu_{3 j}\right)$ are unknown threshold parameters. The parameters are estimated by maximum likelihood, and the corresponding standard errors are clustered at the prefecture level and are robust to heteroskedasticity.

Table 3 provides the estimation results. For each practice, the coefficient of ems is positive and statistically significant at the $1 \%$ level. These results imply that individuals working for organizations with EMSs are more likely to be engaged in energy saving practices at home than those working for organizations without EMSs, which is consistent with our hypothesis. To see the extent of the effects, Fig. 2 depicts the average partial effects of EMSs. For each practice, the probability of "fairly often" increases by 13-19 percentage points when ems changes from zero to one, while the probability of "never" decreases by 6-13 percentage points. According to these estimates, the effects of EMSs on energy saving practices at home do not seem negligible in size.

\subsection{Endogeneity of EMSs}

In Eq. (1), we implicitly assumed that the key regressor,ems, is not correlated with the error term, $u_{j}$; thus,ems is treated as an exogenous variable. This assumption does not seem to be unreasonable because it is not individuals but organizations that determine whether to implement EMSs. One might argue, however, that ems is potentially endogenous due to some omitted factors. For example, consider environmental consciousness, i.e., the extent to which an individual is environmentally conscious. This factor is expected to influence the propensity for the energy saving practice,esp $p_{j}^{*}$. However, it seems difficult to completely control for this factor; a variable based on the survey question "(h)ow much are you concerned about global 

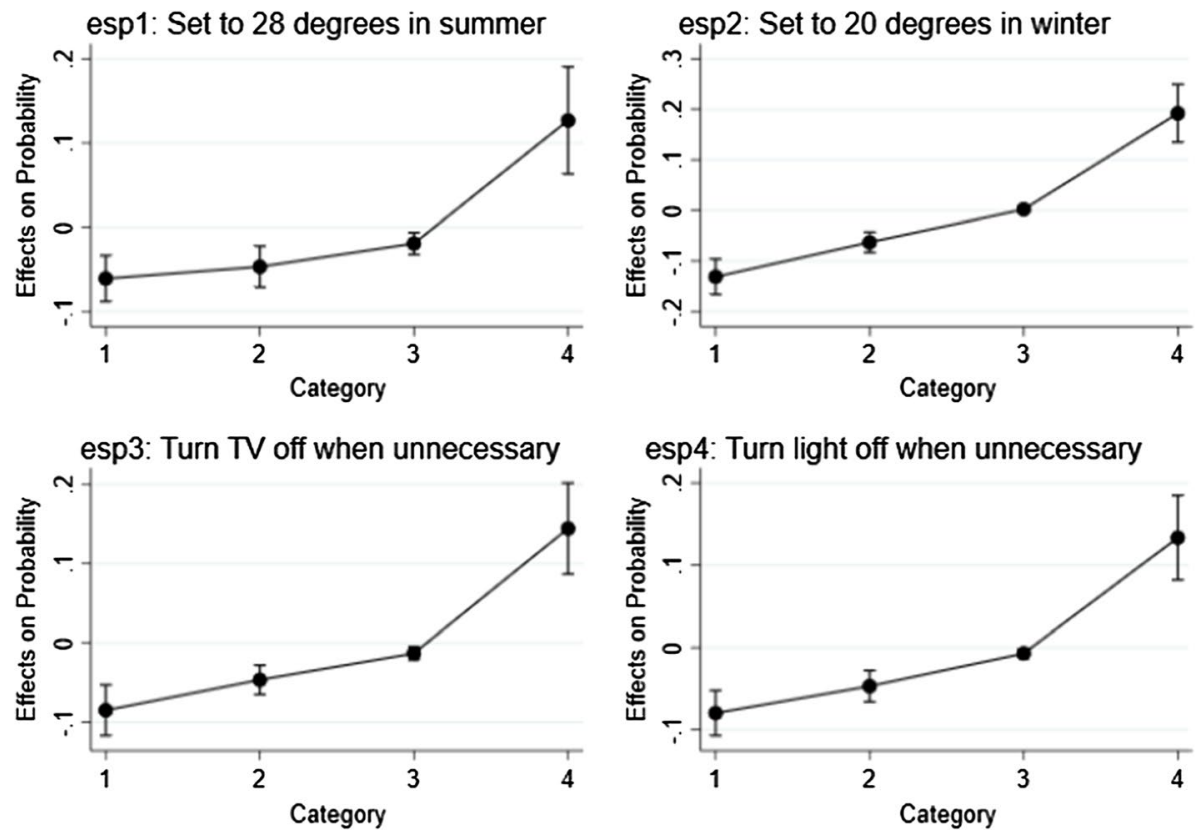

Fig. 2 Average partial effects of EMSs on energy saving practices

warming?" may be a good proxy but is unlikely to be a perfect measure. For this reason, at least part of environmental consciousness is expected to be contained in the error term. Environmental consciousness may also be associated with the desire to work in an environmentally friendly organization, which could influence the probability of being employed in such an organization. Thus, the error term could be correlated with whether the individual works in an organization with an EMS given that environmentally friendly organizations tend to implement EMSs.

To address this issue, we apply the method developed by Terza et al. (2008), which is a nonlinear version of the Hausman (1978) endogeneity test. For our purpose, we slightly modify Eq. (1) as follows:

$$
e s p_{j}^{*}=\alpha_{j} \cdot e m s+\boldsymbol{x} \boldsymbol{\beta}_{j}+\rho_{j} \cdot \omega_{j}+v_{j},
$$

where $\omega_{j}$ captures a set of unobserved factors that are uncorrelated with $\boldsymbol{x}$ but correlated with ems(e.g., environmental consciousness), $\rho_{j}$ is the corresponding parameter, and $v_{j}$ captures a set of unobserved factors that are not correlated with ems or $\omega_{j}$ and is assumed to follow a standard normal distribution. Conditional on ems, $x$, and $\omega_{j}$, the response probability that $e s p_{j}=1$ can be derived as follows:

$$
\operatorname{Pr}\left(e s p_{j}=1\right)=\Phi\left(\mu_{1 j}-\alpha_{j} \cdot e m s-\boldsymbol{x} \boldsymbol{\beta}_{j}-\rho_{j} \cdot \omega_{j}\right),
$$

where $\Phi(\bullet)$ is the standard normal distribution function. The other response probabilities can be derived similarly. A problem of endogeneity emerges due to the presence of $\omega_{j}$; if an ordered probit model is estimated via maximum likelihood without dealing with $\omega_{j}$, the estimator will be inconsistent unless $\rho_{j}=0$. 
Table 3 Estimation Results for Energy Saving Practices

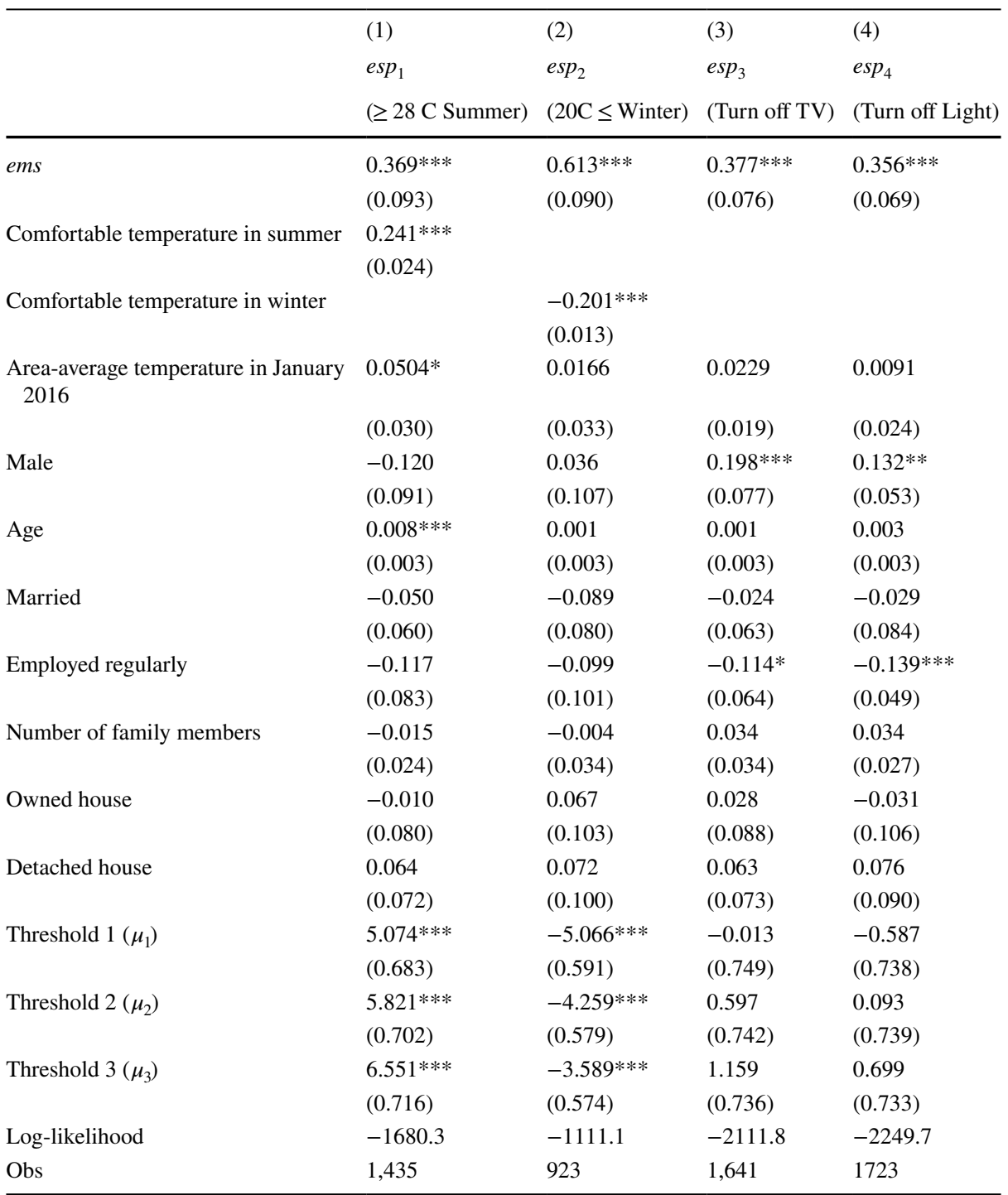

Standard errors clustered by prefecture are presented in parentheses. ***, **, and * correspond to the one, five, and ten percent levels of significance, respectively. Dummy variables for education, for occupation, for the industry the respondent works in, for household income, for prefectures, and TV types are included in each model, although the results are not presented here for the sake of saving space

We next define a reduced form equation that formalizes the relationship between ems and $\omega_{j}$ as follows:

$$
e m s=g\left(\boldsymbol{x} \gamma_{j}+z \delta_{j}\right)+\omega_{j}
$$

where $\left(\gamma_{j}, \delta_{j}\right)^{\prime}$ are unknown parameters, $g(\bullet)$ is some function, and $z$ is an identifying instrument. The variable $z$ must satisfy the following conditions: (A) it is sufficiently correlated 
with ems, (B) it is not correlated with $\omega_{j}$, and (C) it can neither have a direct influence on esp nor be correlated with $v_{j}$. With a particular functional form for $g(\bullet)$, Eq. (3) becomes a well-known binary choice model. In this analysis, by setting $g(\bullet)$ to be the standard normal distribution function, the equation represents a probit model.

Given the response probabilities and Eq. (3), we can control for the endogeneity of ems by using the following two-stage procedure. In the first stage, we estimate Eq. (3) using maximum likelihood and compute the residual as follows: $\widehat{\omega}_{j}=e m s-g\left(x \hat{\gamma}_{j}+z \hat{\delta}_{j}\right)$. In the second stage, we estimate the ordered probit model represented by the response probabilities by substituting $\widehat{\omega}_{j}$ into $\omega_{j}$. The null hypothesis that $\rho_{j}=0($ i.e., the exogeneity of $e m s)$ can be tested by using a conventional $t$-test.

As an instrumental variable, we use the number of employees in the organization at which the individual works as previously mentioned. There are several reasons for this variable to be a relevant instrument. First, according to previous studies (e.g., Nakamura et al. 2001), the organization size (as measured by the number of employees) is positively correlated with EMS certification likely because the fixed costs of certification are less significant for large organizations than for small ones. The number of employees is therefore expected to be correlated with ems and thereby satisfies condition (A) unless a large number of organizations implement EMSs without certification. Second, it does not seem plausible that the number of employees in the individual's organization has a direct influence on whether (s)he is engaged in energy saving practices at home. In addition, a priori, there is little reason to think that the size of the organization is systematically associated with the extent to which its employees are environmentally conscious. ${ }^{7}$ For these reasons, the number of employees in the organization at which the individual works is unlikely to be correlated with $v_{j}$ in Eq. (2) or $\omega_{j}$ in Eq. (3). We therefore assume that it satisfies conditions (B) and (C). However, we acknowledge that the exclusion restriction may be a strong assumption in our estimation. Therefore, in Sect. 4, we do several checks to probe the results in this subsection.

Table 4 provides the results. As shown in Columns (1), (3), (5), and (7), the first stage results are as expected. In each case, the dummy variables for the number of employees are positively correlated with ems. In addition, almost all coefficients are found to be significant at the one percent level, suggesting that the instrument is not weak. These results therefore confirm that the number of employees satisfies condition (A) for a valid instrument.

Columns (2), (4), (6), and (8) provide the second stage results. The estimated coefficients of ems are positive for all practices but not significant for three of the four practices, providing less support for our hypothesis than the results obtained under the exogeneity assumption. However, these results should be somewhat discounted by the fact that ems is better treated as exogenous than endogenous as indicated by the evidence suggesting that the estimated coefficients of the first stage residual $\left(\widehat{\omega}_{j}\right)$ are far from significant $(p>0.5)$. As the standard errors are unnecessarily large due to controlling for endogeneity, which is

\footnotetext{
7 One might argue that the firm size may fail to pass the exclusion restriction. The argument starts by noting that the firm size could be a proxy for the city size because firms in cities tend to be larger than those in rural areas. To the extent that firms in larger cities tend to be more environmentally conscious, the firm size could also capture the degree of environmental consciousness. It then follows that the size of a firm may be associated with the extent to which its employees are environmentally conscious, because environmentally conscious firms tend to hire environmentally conscious individuals. This argument suggests a possible correlation between firm size and individual environmental consciousness, threatening the use of firm size as our instrument. To deal with this issue, we therefore control for prefecture fixed effects in the estimation by noting that this correlation disappears once city size is controlled for.
} 


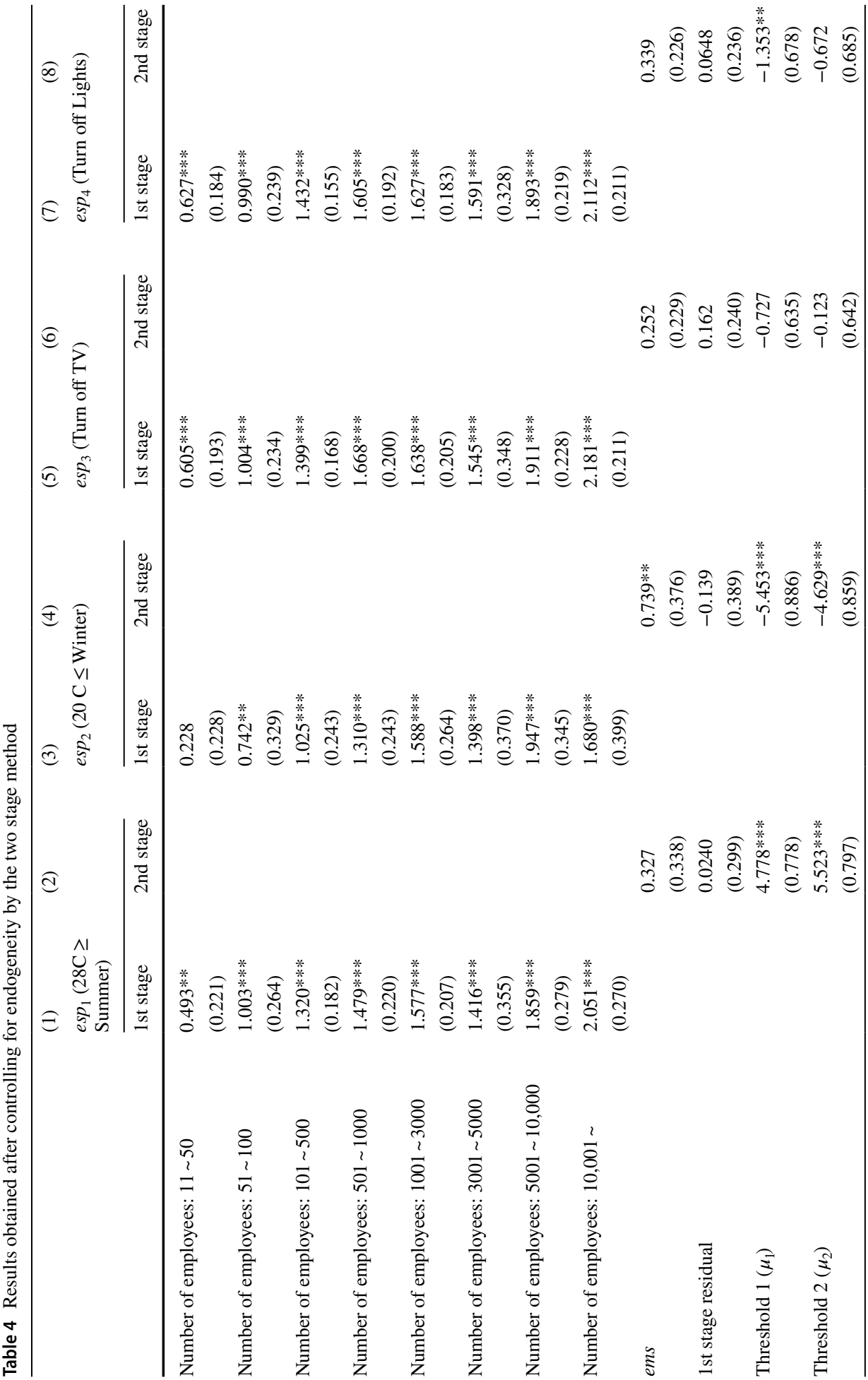




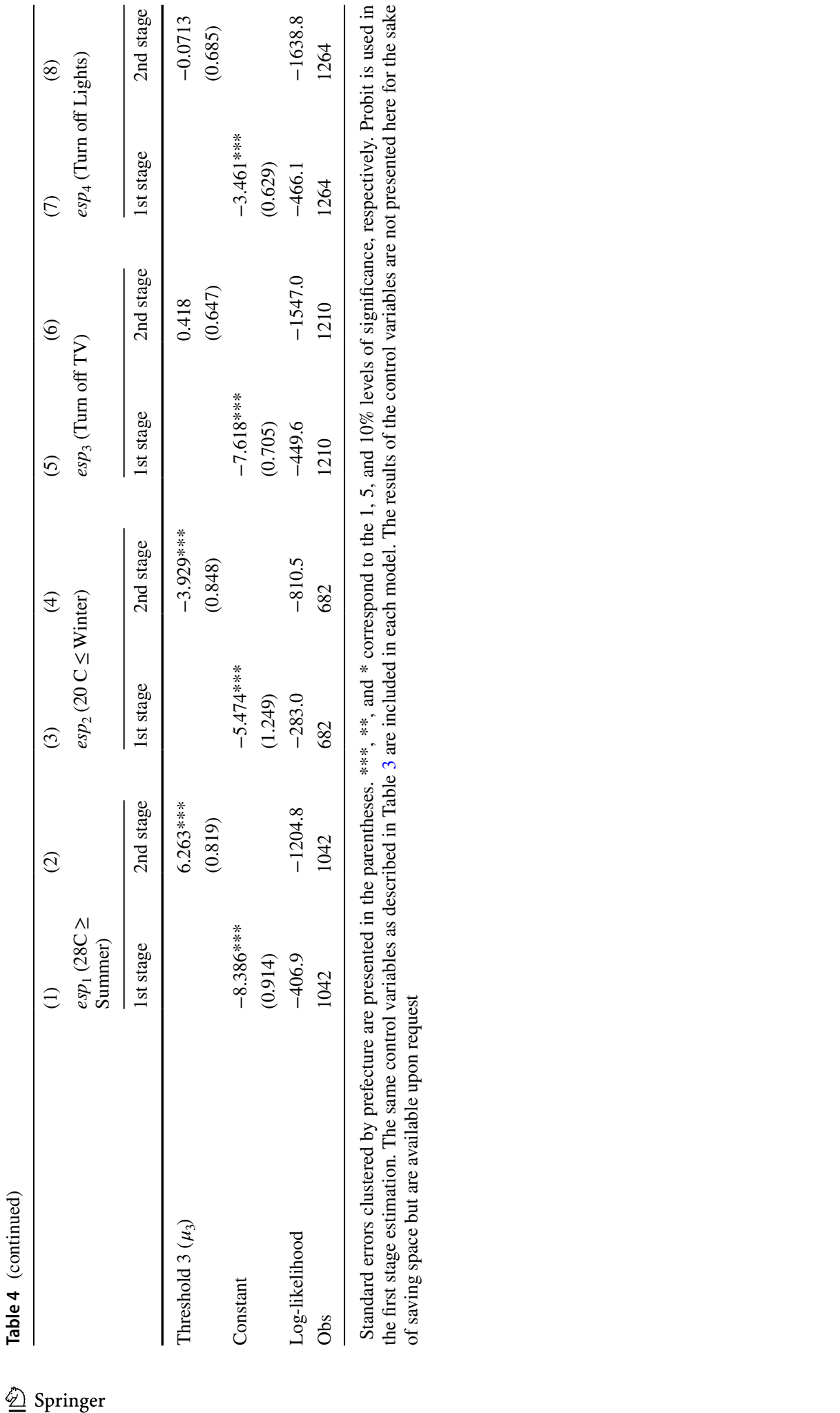


actually absent, the results under the endogeneity assumption (Table 4) are likely to be less accurate than those under the exogeneity assumption (Table 3).

As an alternative way of addressing the potential endogeneity of ems, we consider the joint estimation of five equations, i.e., the four practice equations plus the ems equation. We assume that all latent error terms are normally distributed, allowing them to be arbitrarily correlated. ${ }^{8}$ In this exercise, we only use the respondents who answered all questions regarding the four practices, and accordingly, the number of observations is reduced to 878 . The estimation is performed by maximum likelihood.

The results are presented in Table 5. In all four practices, the estimated coefficients of ems are positive and significant at least at the $10 \%$ level (Columns (1)-(4)), which supports our hypothesis. Notably, the strength of the statistical significance increases, possibly because the joint estimator is generally more efficient than the two-stage estimator in each practice equation. We conduct a Wald test of the joint null hypothesis that the coefficients of ems are zero in all practices. The null is rejected at the $1 \%$ level of significance, implying that ems plays an important role in at least one practice.

\section{Issues Associated with the Instrument and Endogeneity}

\subsection{Exogeneity of the Number of Employees-Informal Check}

We used the number of employees as an instrument for the key regressor,ems, i.e., the dummy variable for whether the respondent's workplace implements an EMS. However, one might question the exogeneity of the instrument by arguing that the number of employees is associated with the firm's environmental friendliness, which, in turn, is associated with its employees' environmental consciousness (captured in the error term). The latter association may occur because job seekers prefer organizations whose values are aligned with their personal values (Cable and Judge 1996). The association also seems consistent with recent evidence suggesting that when job seekers are more concerned about CSR, they place more weight on CSR aspects in their employer choice (Klimkiewicz and Oltra 2017).

To address this issue, we first examine whether the respondents considered the firms' environmental activities essential factors when obtaining their jobs in the current organizations. Therefore, we use the following questions in the survey: "(w)hat were the three most important factors when you chose to work at the current organization? Select three items from the following list: (1) year of establishment, (2) amount of stated capital, (3) number of employees, (4) type and nature of the business, (5) location of the main office, (6) principal shareholders, (7) number of branches, (8) number of affiliated companies, (9) sales and financial conditions, (10) average salary, (11) environmental activities, (12) management philosophy, and (13) average seniority." The proportion of respondents answering "yes" in response to each item is presented in Table 6. The results show that while most respondents answered "yes" to "type and nature of the business" (83.1\%) and "average salary" (50.4\%), very few respondents $(3.7 \%)$

${ }^{8}$ Specifically, the model is as follows:

$$
\begin{gathered}
e c p_{j}^{*}=\alpha_{j} \cdot e m s+\boldsymbol{x} \boldsymbol{\beta}_{j}+\varepsilon_{j}, j=1,2,3,4 \\
e m s=I(\boldsymbol{x} \gamma+z \delta+u>0), \\
{\left[\varepsilon_{1}, \varepsilon_{2}, \varepsilon_{3}, \varepsilon_{4}, u\right] \mid \boldsymbol{x}, z \sim N_{5}(\mathbf{0}, \boldsymbol{\Sigma}),}
\end{gathered}
$$

where $\Sigma$ is a variance-covariance matrix where in which all diagonal terms are normalized to one. 


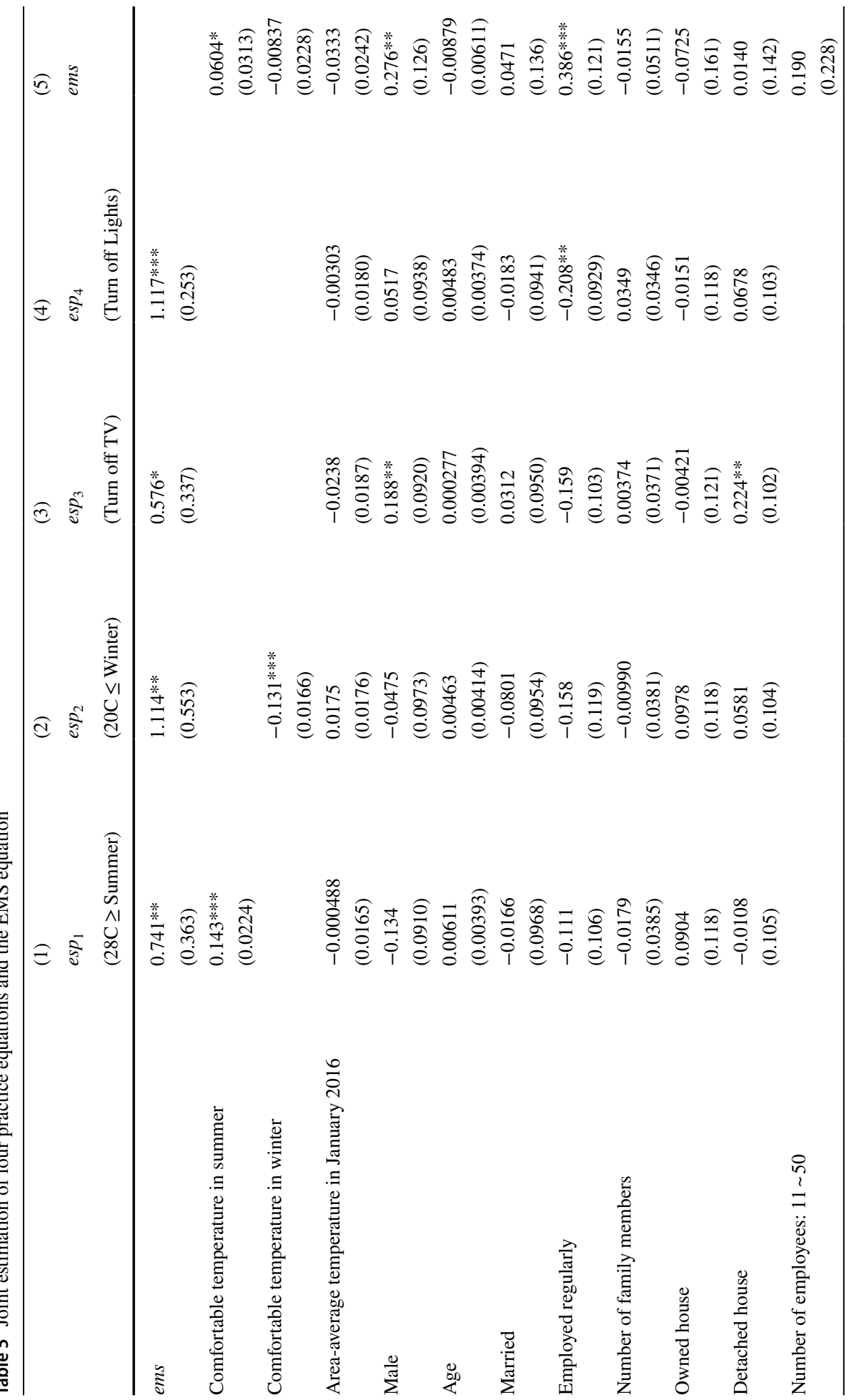




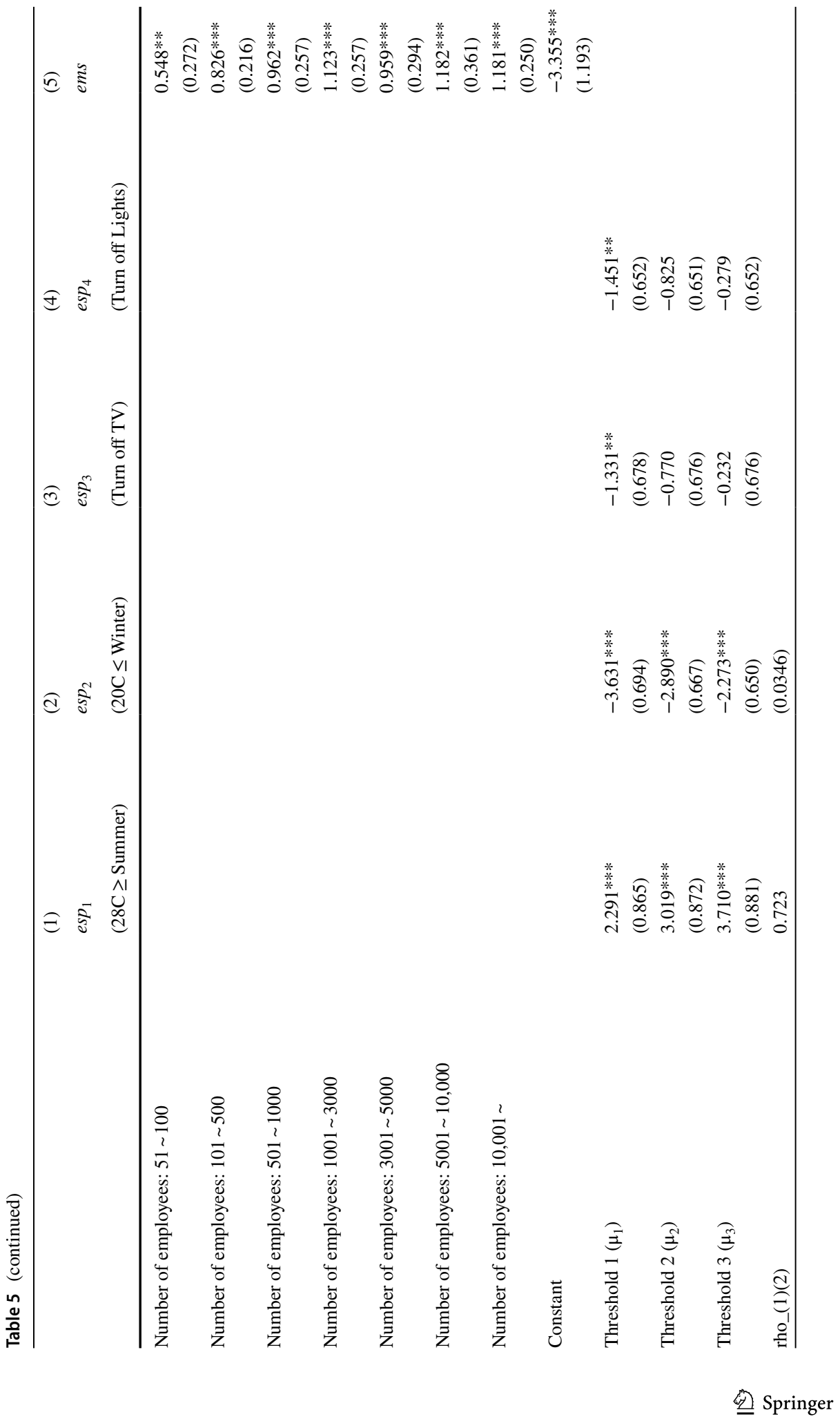




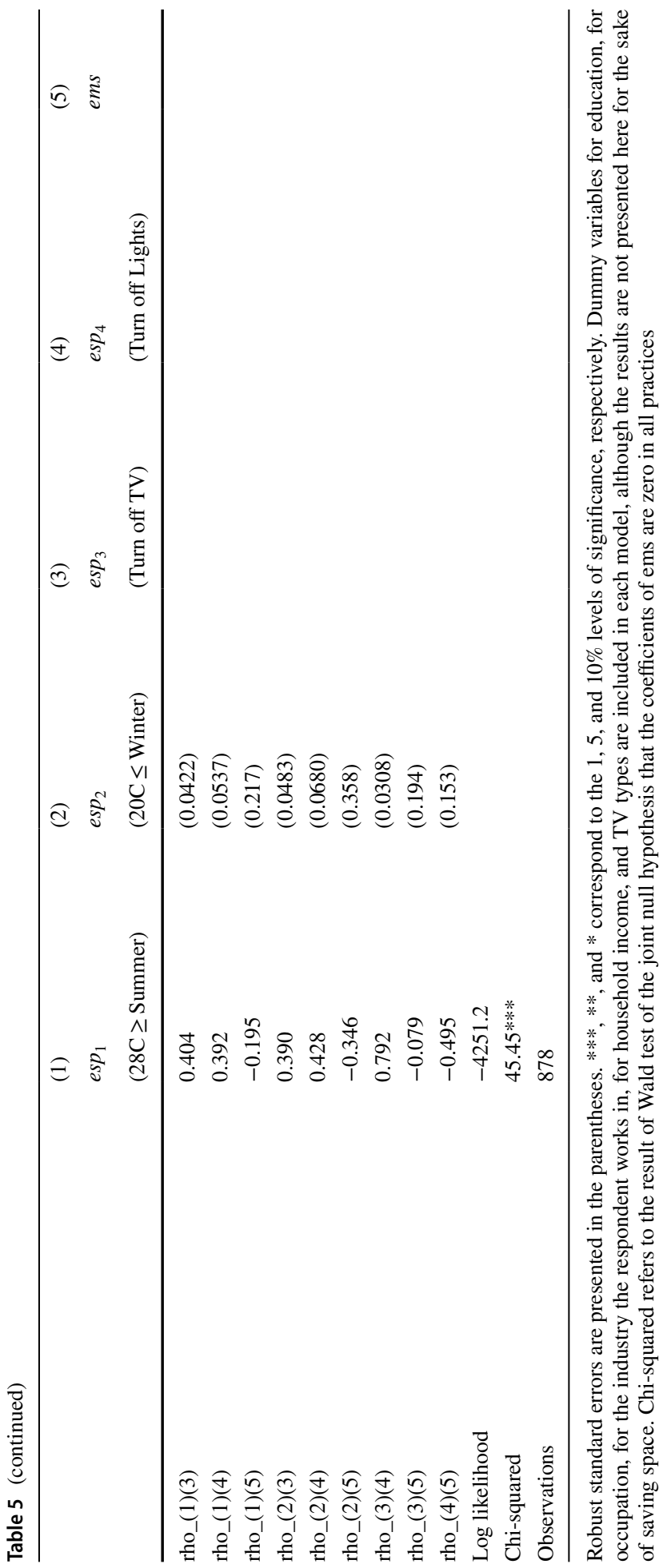


Table 6 Percentage of respondents who answered yes to each item

\begin{tabular}{lllll}
\hline & ALL & ems $=0$ & ems $=1$ & $t$-value \\
\hline Year of establishment & 0.076 & 0.076 & 0.075 & 0.081 \\
Amount of stated capital & 0.080 & 0.071 & 0.121 & $-2.518^{* *}$ \\
Number of employees & 0.247 & 0.255 & 0.208 & $1.791^{*}$ \\
Type and nature of the business & 0.831 & 0.833 & 0.821 & 0.519 \\
Location of the main office & 0.487 & 0.501 & 0.420 & $2.604 * * *$ \\
Principal shareholders & 0.033 & 0.032 & 0.033 & -0.008 \\
Number of branches & 0.066 & 0.066 & 0.065 & 0.079 \\
Number of affiliated companies & 0.018 & 0.013 & 0.039 & $-2.233^{* *}$ \\
Sales and financial conditions & 0.175 & 0.154 & 0.274 & $-4.394 * *$ \\
Average salary & 0.504 & 0.496 & 0.537 & -1.303 \\
Environmental activities & 0.037 & 0.035 & 0.046 & -0.798 \\
Management philosophy & 0.263 & 0.266 & 0.251 & 0.563 \\
Average seniority & 0.183 & 0.199 & 0.111 & $4.241^{* * *}$ \\
\hline
\end{tabular}

The number of observations in ALL, ems $=0$ and $e m s=1$ is $1723,1,416$ and 307 , respectively. The last column presents the results of the mean-comparison tests between two groups. ***, **, and * correspond to the 1,5 , and $10 \%$ levels of significance, respectively

answered "yes" to "environmental activities," suggesting that most respondents did not place much weight on environmental factors.

We regress the answer of "environmental activities" on the number of employees. The coefficient is expected to be positive if the above argument is correct; large firms attract environmentally conscious job seekers to a greater extent than small firms, and consequently, those who work for large firms are more likely to be environmentally conscious than those who work for small firms. However, the regression results do not provide strong support for this argument. Despite being positive, the estimated coefficient is not significant at the $10 \%$ level (Column 1 in Table 7). When control variables are included in the regression, the estimated coefficient becomes even less favorable for the argument because it is negative (and remains statistically insignificant). Overall, these results suggest that the firm size may not be systematically associated with employees' environmental consciousness, providing some support for the exogeneity of our instrument.

\subsection{Using Heteroskedasticity for Identification}

Despite providing some supporting evidence, we cannot fully assure that our instrument satisfies the exogeneity assumption. Therefore, we complement the IV results with results based on the method proposed by Lewbel $(2012,2018)$. Lewbel's estimator can be applied to a triangular system of linear equations when no outside instruments are available. The model parameters are identified under the condition that some regressors are uncorrelated with the product of heteroskedastic errors. Next, we briefly explain the estimator in our context. For more details, we refer the reader to the article by Lewbel (2012).

The model consists of the following two equations:

$$
\text { besp }=\alpha \cdot e m s+\boldsymbol{x} \boldsymbol{\beta}_{1}+\varepsilon_{1},
$$


Table 7 Estimation results of environmental activities

\begin{tabular}{|c|c|c|}
\hline & (1) & (2) \\
\hline Number of employees & $\begin{array}{l}0.00719 \\
(0.0295)\end{array}$ & $\begin{array}{l}-0.0106 \\
(0.0313)\end{array}$ \\
\hline $\begin{array}{l}\text { Area-average temperature in Janu- } \\
\text { ary } 2016\end{array}$ & & $\begin{array}{l}-0.107^{* * *} \\
(0.0416)\end{array}$ \\
\hline Male & & $\begin{array}{l}-0.148 \\
(0.136)\end{array}$ \\
\hline Age & & $\begin{array}{l}-0.0151 * * * \\
(0.00549)\end{array}$ \\
\hline Married & & $\begin{array}{l}0.101 \\
(0.0939)\end{array}$ \\
\hline Employed regularly & & $\begin{array}{l}-0.155 \\
(0.186)\end{array}$ \\
\hline Number of family members & & $\begin{array}{l}0.00741 \\
(0.0533)\end{array}$ \\
\hline Owned house & & $\begin{array}{l}0.147 \\
(0.152)\end{array}$ \\
\hline Detached house & & $\begin{array}{l}-0.130 \\
(0.155)\end{array}$ \\
\hline Constant & $\begin{array}{l}-1.811^{* * * *} \\
(0.141)\end{array}$ & $\begin{array}{l}-1.665^{* *} \\
(0.729)\end{array}$ \\
\hline Log-likelihood & -273.5 & -227.5 \\
\hline Observations & 1723 & 1,456 \\
\hline
\end{tabular}

Standard errors clustered by prefecture are presented in the parentheses. $* * *, * *$, and * correspond to the 1,5 , and $10 \%$ levels of significance, respectively. Dummy variables for education, for occupation, for the industry the respondent works in, for household income, and for prefectures are included in model (2), although the results are not presented here for the sake of saving space

$$
e m s=\boldsymbol{x} \boldsymbol{\beta}_{2}+\varepsilon_{2},
$$

where besp is a binary indicator that takes one if the individual engages in the energy saving practice, $\boldsymbol{x}$ is a vector of exogenous regressors and ems is an endogenous regressor that is correlated with the error term $\varepsilon_{1}$. In this estimation, we transform the ordered categorical variable, esp, into a binary variable, besp, as follows: besp $=1$ if $e s p=\varepsilon$ fairyoften(4)e. Both Eqs. (4) and (5) are linear probability models (LPMs), and accordingly, the coefficient of a variable represents its marginal effect on the response probability.

In the standard instrumental variable method, it is assumed that at least one of the elements of $\boldsymbol{\beta}_{1}$ is zero (i.e., exclusion restrictions). However, Lewbel's (2012) method assumes that a variable, $z$, that satisfies the following two conditions exists:

$$
\operatorname{COV}\left(z, \varepsilon_{1} \varepsilon_{2}\right)=0
$$

and 


$$
\operatorname{COV}\left(z, \varepsilon_{2}^{2}\right) \neq 0
$$

Here, $z$ can be $\boldsymbol{x}$ or a subset of $\boldsymbol{x}$ or $\boldsymbol{x}$ itself. Lewbel (2012) shows that two-stage least squares provide a consistent estimator of $\alpha$ by using as instrumental variables $\boldsymbol{x}$ and $(z-\bar{z}) \hat{\varepsilon}_{2}$ where $\bar{z}$ is the sample average of $z$, and $\widehat{\varepsilon}_{2}$ is the estimated residual of Eq. (5). Notably, condition (6) cannot be statistically tested just as the exogeneity of an instrument in the standard instrumental variables method. Condition (7) is always satisfied for a LPM because the error term in a LPM is inherently heteroskedastic.

The estimation results are presented in Table 8, and Columns (1), (3), (5), and (7) provide the OLS results for comparison. Regarding each energy saving practice, the estimated coefficient of ems is positive and significant at the 5\% level. According to the point estimates, those with ems $=1$ are 11-18\% more likely to "fairly often" engage in an energy saving practice than those with ems $=0$ (Columns (2), (4), (6), and (8)). We obtain qualitatively similar results when using a different definition for besp. Notably, the reported marginal effects are quite similar in magnitude to those on the probability of "fairy often (4)" reported in Fig. 2. Therefore, our main results seem to be robust to the estimation methods.

\subsection{Using Equal Correlation Restriction for Identification}

To further check the robustness of our main results, we use the approach developed by Altonji et al. (2005) to construct a bivariate probit model with an endogenous dummy regressor. In this approach, identification is achieved by imposing certain assumptions on the importance of observables and unobservables in the reduced-form equation of the endogenous dummy. This approach supplements our IV analysis as it does not rely on any instruments similar to Lewbel's method.

To explain the approach in our context, let the outcome of interest besp be a function of a latent variable besp $^{*}$ determined as follows:

$$
\text { besp }^{*}=\alpha \cdot e m s+\boldsymbol{x} \boldsymbol{\beta}_{1}+\varepsilon_{1},
$$

where $\operatorname{COV}\left(\boldsymbol{x}, \varepsilon_{1}\right)=0$ holds. ${ }^{9}$ Similarly, let ems be a function of a latent variable $e m s^{*}$ whose linear projection on $\boldsymbol{x} \boldsymbol{\beta}_{1}$ and $\varepsilon_{1}$ can be expressed as follows:

$$
\operatorname{Proj}\left(e m s^{*} \mid \boldsymbol{x} \boldsymbol{\beta}_{1}, \varepsilon_{1}\right)=\varphi_{0}+\varphi_{x \boldsymbol{\beta}_{1}} \cdot \boldsymbol{x} \boldsymbol{\beta}_{1}+\varphi_{\varepsilon_{1}} \cdot \varepsilon_{1}
$$

Here, $\varphi_{x \beta_{1}}\left(\varphi_{\varepsilon_{1}}\right)$ indicates the relationship between EMS implementation and the observable (unobservable) component of the individual's energy saving practice, which is interpreted as the degree of selection on observables (unobservables).

Two conditions on $\varphi_{\varepsilon_{1}}$ representing extreme assumptions regarding the degree of selection on unobservables provide the identifying information for the upper and lower bound estimates of the EMS effect on an individual's energy saving practice. The first extreme condition (called condition 1) is $\varphi_{\varepsilon_{1}}=0$. If this condition holds, there is no endogeneity of EMS. The second extreme condition (called condition 2) is $\varphi_{\varepsilon_{1}}=\varphi_{x \beta_{1}}$, which is the equal correlation condition (i.e., the degree of the selection on the unobservables is the same as that of the selection on the observables). One situation where condition 2 is satisfied

\footnotetext{
${ }^{9}$ Notably, although the observables $\boldsymbol{x}$ and the unobserved error are unlikely to be unrelated, we can redefine $\boldsymbol{\beta}_{1}$ and $\varepsilon_{1}$ such that they are not correlated. Hence, the parameter vector $\boldsymbol{\beta}_{1}$ measures the direct impact of observables on besp* and the part of unobsevables that is correlated with observables.
} 


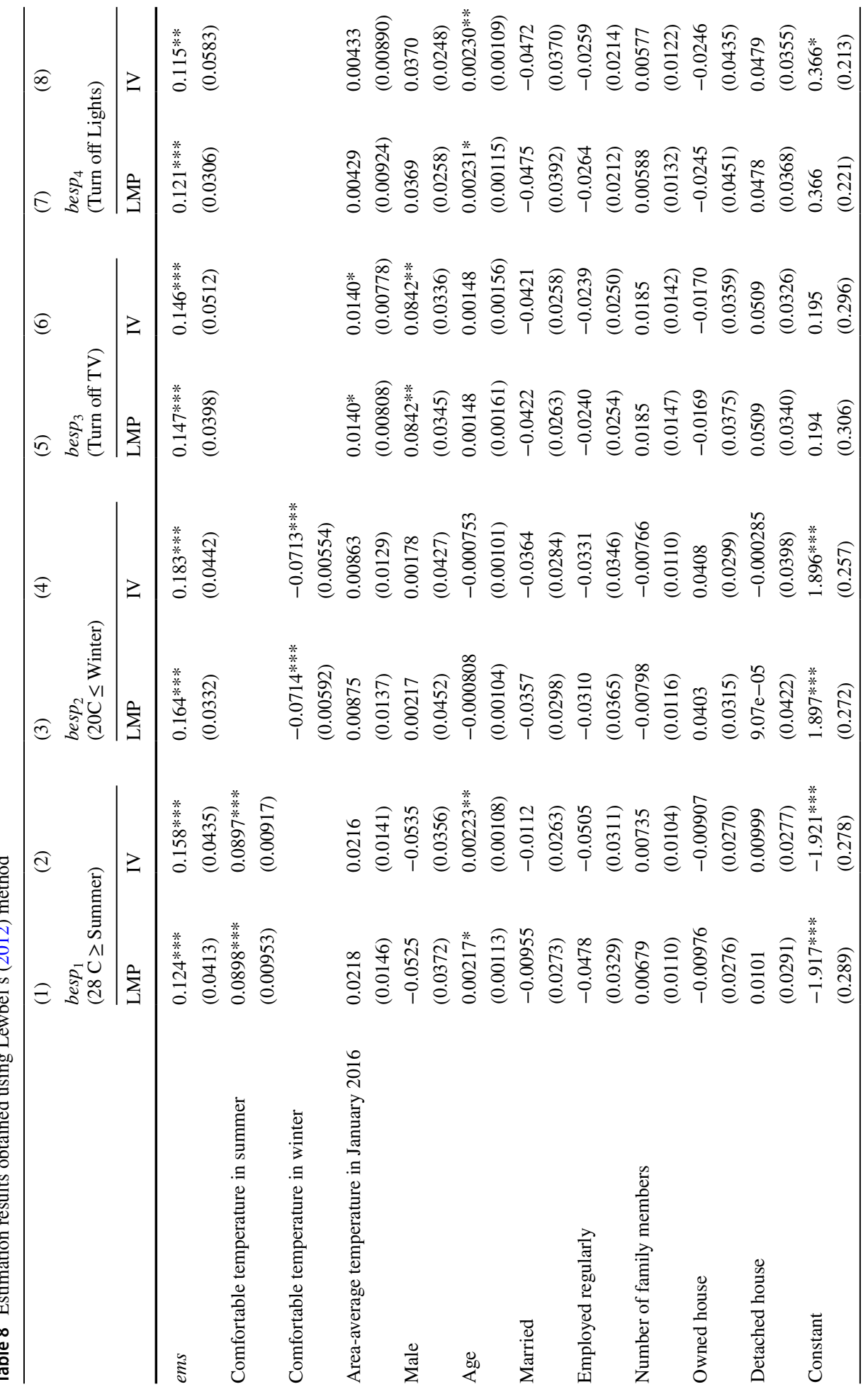




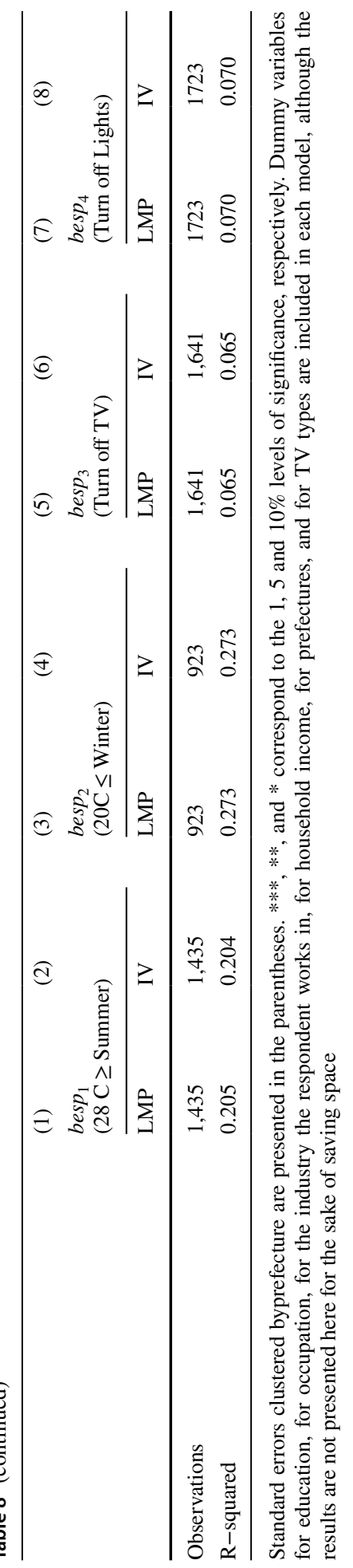


Table 9 Average partial effects of EMS — different assumptions regarding the selection onunobservables

\begin{tabular}{|c|c|c|c|c|c|c|c|c|}
\hline & \multicolumn{6}{|c|}{ Constraints on the correlation of the disturbances } & \multirow{2}{*}{\multicolumn{2}{|c|}{$\begin{array}{l}\text { Altonji, Elder \&Taber } \\
(2005) \\
(7)\end{array}$}} \\
\hline & \multirow{3}{*}{$\begin{array}{l}\rho(1) \\
\rho=0.0 \\
\text { APE }\end{array}$} & \multirow{3}{*}{$\begin{array}{l}(2) \\
\rho=0.1 \\
\text { APE }\end{array}$} & \multirow{3}{*}{$\begin{array}{l}\rho(3) \\
\rho=0.2 \\
\text { APE }\end{array}$} & \multirow{3}{*}{$\begin{array}{l}\text { (4) } \\
\rho=0.3 \\
\text { APE }\end{array}$} & \multirow{3}{*}{$\begin{array}{l}\rho(5) \\
\rho=0.4 \\
\text { APE }\end{array}$} & \multirow{3}{*}{$\begin{array}{l}(6) \\
\rho=0.5 \\
\text { APE }\end{array}$} & & \\
\hline & & & & & & & $\rho=\frac{\operatorname{Cov}(x \boldsymbol{\beta}}{\operatorname{Var}(x}$ & \\
\hline & & & & & & & APE & $\rho$ \\
\hline $\begin{array}{l}e s p_{1} \\
(\geq 28 \mathrm{C} \mathrm{S}\end{array}$ & $\begin{array}{l}0.1201 * * * \\
\operatorname{l1}(0 \mathrm{r}) \mathrm{a} 2 \beta)\end{array}$ & $\begin{array}{l}0.0617^{*} \\
(0.0347)\end{array}$ & $\begin{array}{l}0.0008 \\
(0.0342)\end{array}$ & $\begin{array}{l}-0.0592 * \\
(0.0330)\end{array}$ & $\begin{array}{l}-0.1195^{* * *} \\
(0.0311)\end{array}$ & $\begin{array}{l}-0.1786^{* * *} \\
(0.0287)\end{array}$ & $\begin{array}{l}0.1137 * * * \\
(0.0351)\end{array}$ & $\begin{array}{l}0.0000 \\
(0.1147)\end{array}$ \\
\hline $\begin{array}{l}e s p_{2} \\
(\leq 20 \mathrm{C})\end{array}$ & $\begin{array}{l}0.1560^{* * *} \\
\text { if(teß) } 41)\end{array}$ & $\begin{array}{l}0.1103 * * * \\
(0.0389)\end{array}$ & $\begin{array}{l}0.0563 \\
(0.0379)\end{array}$ & $\begin{array}{l}0.0008 \\
(0.0364)\end{array}$ & $\begin{array}{l}-0.0503 \\
(0.0346)\end{array}$ & $\begin{array}{l}-0.1023 * * * \\
(0.0324)\end{array}$ & $\begin{array}{l}0.1600 * * * \\
(0.0394)\end{array}$ & $\begin{array}{l}0.0000 \\
(0.1148)\end{array}$ \\
\hline$e s p_{3}$ & $0.1499 * * *$ & $0.0843 * * *$ & 0.0160 & -0.0527 & $-0.1183^{* * *}$ & $-0.1818 * * *$ & -0.0180 & 0.2460 \\
\hline $\begin{array}{c}\text { (Turn off } \\
\text { TV) }\end{array}$ & $(0.0326)$ & $(0.0356)$ & $(0.0349)$ & $(0.0333)$ & $(0.0310)$ & $(0.0281)$ & $(0.1081)$ & $(0.1707)$ \\
\hline$e s p_{4}$ & $0.1248 * * *$ & $0.0621 *$ & -0.0054 & $-0.0682 * *$ & $-0.1314 * * *$ & $-0.1894 * * *$ & -0.0370 & 0.2562 \\
\hline $\begin{array}{c}\text { (Turn off } \\
\text { Light) }\end{array}$ & $(0.0315)$ & $(0.0341)$ & $(0.0329)$ & $(0.0309)$ & $(0.0283)$ & $(0.0254)$ & $(0.1140)$ & $(0.1875)$ \\
\hline
\end{tabular}

Standard errors are presented in the parentheses. ***, **, and * correspond to the 1, 5, and $10 \%$ levels of significance, respectively. The same control variables as described in the estimation of energy saving practices in Sect. 3 are included, except for the dummy variables for prefectures in each model and a dummy variable for occupation 'Maintenance' only in the winter air conditioner practice due to the sample size, although the results are not presented here for the sake of saving space

is that the observables are selected at random from the full set of factors that determine the outcome of interest. Although such a situation is less likely to hold exactly in practice, this condition provides a ceiling value of $\varphi_{\varepsilon_{1}}$; the relationship between the observables and EMS would not be weaker than the relationship between the unobservables and EMS (for more details, see Altonji et al. (2005) for discussions regarding condition 2). Therefore, the degree of the selection on unobservables is constrained as follows: $0 \leq \varphi_{\varepsilon_{1}} \leq \varphi_{x \beta_{1}}$. For the estimation, we specify the latent variable for ems as follows:

$$
e m s^{*}=\boldsymbol{x} \boldsymbol{\beta}_{2}+\varepsilon_{2},
$$

where $\boldsymbol{\beta}_{2}$ is a vector of parameters corresponding to $\boldsymbol{x}, \varepsilon_{2}$ is the unobserved error, and $\operatorname{COV}\left(\boldsymbol{x}, \varepsilon_{2}\right)=0$. We assume that the errors $\left(\varepsilon_{1}, \varepsilon_{2}\right)$ are jointly standard normally distributed with correlation coefficient $\rho$. Then, the degree of the selection on unobservables $\left(\varphi_{\varepsilon_{1}}\right)$ (in relation to the degree of the selection on observables $\left(\varphi_{x \beta_{1}}\right)$ ) can be re-expressed by using the correlation coefficient. In particular, it can be shown that condition 2 is equivalent to $\rho=\frac{\operatorname{Cov}\left(x \beta_{1}, x \beta_{2}\right)}{\operatorname{Var}\left(x \beta_{1}\right)}$. This implies that the maximum likelihood estimation of a bivariate probit with the constraint that $\rho=\frac{\operatorname{Cov}\left(x \beta_{1}, x \beta_{2}\right)}{\operatorname{Var}\left(x \beta_{1}\right)}$ provides the lower bound estimates of the EMS effect.

Table 9 displays the estimates of the EMS effects that correspond to various assumptions regarding the selection on unobservables for all four energy saving practices. In Columns (1)-(6), we see how sensitive the estimates are as the correlation parameter $\rho$ changes from 0.0 to 0.5 . For the summer air conditioner practice, when $\rho=0$, the average partial effect (APE) of ems is 0.120 , and this effect declines to 0.062 when $\rho=0.1$ and to 0.001 when $\rho=0.2$. Thus, when sampling error is ignored, the degree of the selection on unobervables would have to be larger than 0.2 to explain the estimated effect under the null of 
no causal effect of ems. Similar patterns are observed for the winter air conditioner, TV and light practices. In particular, when $\rho=0$, the APEs of ems are 12-16 percentage points and statistically significant at the $1 \%$ level; when the imposed correlation increases, the APEs of ems decrease.

Columns (7) in Table 9 provides the lower bound estimates of the EMS effects, which are obtained under the extreme assumption of the equality of the selection on observables and unobservables (condition 2). Regarding the summer and winter air conditioner practices, the APE estimates of ems are 0.114 and 0.160 , respectively, which are statistically significant at the $1 \%$ level. These estimates are close to the estimated values obtained using the univariate probit model with ems treated as exogenous and are consistent with our results in the previous subsections.

However, regarding the TV and light practices, the APE estimates of ems are not significant at the $10 \%$ level. The estimates are found to be close to zero, which is attributed to the estimated correlation coefficients $(\rho)$ being approximately 0.25 . Therefore, our results of the TV and light practices may be less robust to the estimation methods than the summer and winter air conditioner practices.

\section{Do EMSs Lower Household Energy Consumption?}

\subsection{The Model}

We now address the second hypothesis: whether household expenditures on electricity use are lower for those who work in organizations with EMSs than for those who do not. We assume that the individual's monthly household expenditure on electricity use (bill $\left.{ }^{*}\right)$ depends on ems, $\boldsymbol{x}$, and the error term $(\varepsilon)$ :

$$
\ln \left(\text { bill }^{*}\right)=\gamma_{0}+\gamma_{1} \cdot e m s+x \phi+\varepsilon
$$

where $\left(\gamma_{0}, \gamma_{1}, \boldsymbol{\phi}^{\prime}\right)$ are unknown parameters and $\varepsilon$ is normally distributed with mean zero and variance $\sigma^{2}$. Due to the design of the survey item used for this analysis, we do not directly observe bill $^{*}$; instead, interval-coded data $($ bill $)$ are available. Specifically, bill $=1$ if bill $^{*}<\tau_{1}(=2$ thousand yen $)$,bill $=2$ if $\tau_{1} \leq$ bill ${ }^{*}<\tau_{2}(=4$ thousand yen $)$, bill $=3$ if $\tau_{2} \leq$ bill $^{*}<\tau_{3}(=6$ thousand yen $)$, bill $=4$ if $\tau_{3} \leq$ bill $^{*}<\tau_{4}(=8$ thousand yen $)$,bill $=5$ if $\tau_{4} \leq$ bill $^{*}<\tau_{5}(=10$ thousand yen $)$, bill $=6$ if $\tau_{5} \leq$ bill $^{*}<\tau_{6}(=12$ thousand yen $)$,bill $=7$ if $\tau_{6} \leq$ bill $^{*}<\tau_{7}(=14$ thousand yen $)$,bill $=8$ if $\tau_{7} \leq$ bill ${ }^{*}<\tau_{8}(=16$ thousand yen $)$,bill $=9$ if $\tau_{8} \leq$ bill $^{*}<\tau_{9}(=18$ thousand yen $)$, bill $=10$ if $\tau_{9} \leq$ bill $l^{*}<\tau_{10}(=20$ thousand yen $)$, and bill $=11$ if bill $^{*} \geq \tau_{10}$. The response probabilities, $\operatorname{Pr}($ bill $=j \mid e m s, \boldsymbol{x}),(j=1, \ldots, 11)$, resemble those of an ordered probit model, except that the threshold parameters $(\tau$ 's) are all known to the researcher. The parameters $\left(\gamma_{0}, \gamma_{1}, \boldsymbol{\phi}^{\prime}, \sigma^{2}\right)$ are estimated by maximum likelihood and can be interpreted as if one had observed bill $l^{*}$ and estimated $E\left(\right.$ bill $\left.^{*} \mid e m s, \boldsymbol{x}\right)$ by ordinary least squares (Wooldridge 2010, page 783).

\subsection{Data}

For this analysis, we use data from another online survey that was conducted in February 2014 in Japan. It included 6500 individuals aged 20 or older. In terms of the survey procedure, we made the same geographical adjustment as explained earlier. After individuals 
Table 10 Means of variables

\begin{tabular}{|c|c|c|c|}
\hline & ALL & $e m s=0$ & $e m s=1$ \\
\hline bill & 5.598 & 5.568 & 5.702 \\
\hline ems & 0.222 & - & - \\
\hline Area-average temperature in January 2014 & 4.750 & 4.703 & 4.916 \\
\hline Male & 0.616 & 0.571 & 0.772 \\
\hline Age & 43.782 & 43.337 & 45.341 \\
\hline Married & 0.610 & 0.588 & 0.685 \\
\hline Employed regularly & 0.635 & 0.588 & 0.797 \\
\hline Number of family members & 2.889 & 2.850 & 3.025 \\
\hline Owned house & 0.665 & 0.649 & 0.719 \\
\hline Detached house & 0.545 & 0.535 & 0.580 \\
\hline Household income (less than 2 million yen) & 0.064 & 0.076 & 0.022 \\
\hline Household income (between 2 million yen and 3 million yen) & 0.102 & 0.119 & 0.045 \\
\hline Household income (between 3 million yen and 4 million yen) & 0.138 & 0.153 & 0.087 \\
\hline Household income (between 4 million yen and 5 million yen) & 0.153 & 0.160 & 0.127 \\
\hline Household income (between 5 million yen and 7 million yen) & 0.218 & 0.213 & 0.236 \\
\hline Household income (between 7 million yen and 10 million yen) & 0.191 & 0.168 & 0.273 \\
\hline Household income (between 10 million yen and 15 million yen) & 0.101 & 0.087 & 0.149 \\
\hline Household income (more than 15 million yen) & 0.032 & 0.024 & 0.062 \\
\hline Educational status (high school) & 0.282 & 0.305 & 0.200 \\
\hline Educational status (higher professional school) & 0.090 & 0.096 & 0.070 \\
\hline Educational status (junior college) & 0.102 & 0.112 & 0.067 \\
\hline Educational status (university) & 0.456 & 0.427 & 0.557 \\
\hline Educational status (graduate school) & 0.054 & 0.042 & 0.098 \\
\hline Educational status (others) & 0.016 & 0.018 & 0.009 \\
\hline Occupation (company executive) & 0.149 & 0.120 & 0.253 \\
\hline Occupation (company employee) & 0.506 & 0.484 & 0.584 \\
\hline Occupation (public worker) & 0.070 & 0.072 & 0.062 \\
\hline Occupation (part-time worker) & 0.274 & 0.324 & 0.101 \\
\hline
\end{tabular}

Numbers of observations in $e m s=0$ and $e m s=1$ are 2,260 and 645, respectively

who were unemployed or provided incomplete answers are excluded, the sample size is reduced to 2905 .

This survey is broadly similar to the one used for the previous analysis in that regarding individual characteristics, it asked about EMSs and sociodemographic and household characteristics. However, this survey did not ask about the number of employees in the organization the respondent works for and therefore does not provide a relevant instrumental variable to control for potential endogeneity of ems. As a result, when estimating Eq. (4), we need to treat ems as an exogenous variable. Admittedly, this assumption seems to be rather strong, but may be less strong than it seems to be, because the results in the previous section are consistently and strongly in favor of the exogeneity of ems.

Table 10 presents the means of each variable of the data. For the variable of electricity expenditure, we use the following survey question: "(h)ow much money did you spend on electricity in January 2014?" Respondents were asked to choose from the eleven responses introduced previously. Figure 1e shows the distributions of electricity expenditures (bill) for 
Table 11 Estimation Results for Electricity Expenditure

\begin{tabular}{|c|c|c|c|}
\hline & (1) & (2) & (3) \\
\hline \multirow[t]{2}{*}{ ems } & $0.0413 *$ & $-0.0335 * *$ & $-0.0591 * * *$ \\
\hline & $(0.0244)$ & (0.0167) & $(0.0179)$ \\
\hline \multirow{2}{*}{$\begin{array}{l}\text { Area-average temperature in } \\
\text { January } 2014\end{array}$} & & -0.00273 & 0.00218 \\
\hline & & $(0.00914)$ & $(0.00975)$ \\
\hline \multirow[t]{2}{*}{ Male } & & $0.0335^{*}$ & $0.0454 * *$ \\
\hline & & (0.0199) & $(0.0187)$ \\
\hline \multirow[t]{2}{*}{ Age } & & $0.0111 * * *$ & $0.00599 * * *$ \\
\hline & & $(0.000915)$ & $(0.000998)$ \\
\hline \multirow[t]{2}{*}{ Married } & & 0.0202 & 0.0235 \\
\hline & & $(0.0168)$ & $(0.0202)$ \\
\hline \multirow[t]{2}{*}{ Employed regularly } & & 0.0232 & -0.0276 \\
\hline & & $(0.0265)$ & $(0.0441)$ \\
\hline \multirow[t]{2}{*}{ Number of family members } & & $0.222 * * *$ & $0.143 * * *$ \\
\hline & & $(0.00957)$ & $(0.0109)$ \\
\hline \multirow[t]{2}{*}{ Owned house } & & & $0.224 * * *$ \\
\hline & & & $(0.0268)$ \\
\hline \multirow[t]{2}{*}{ Detached house } & & & $0.160 * * *$ \\
\hline & & & $(0.0179)$ \\
\hline \multirow[t]{2}{*}{$\ln ($ sigma $)$} & $-0.469 * * *$ & $-0.643 * * *$ & $-0.702 * * *$ \\
\hline & $(0.0188)$ & $(0.0180)$ & $(0.0172)$ \\
\hline \multirow[t]{2}{*}{ Constant } & $9.092 * * *$ & $7.942 * * *$ & $7.944 * * *$ \\
\hline & $(0.0243)$ & (0.0636) & $(0.0943)$ \\
\hline Log-likelihood & -6497.0 & -6019.5 & -5865.4 \\
\hline Chi-squared & $2.87 *$ & $860.1 * * *$ & $9717.6 * * *$ \\
\hline Observations & 2905 & 2905 & 2905 \\
\hline
\end{tabular}

Standard errors clustered by prefecture are presented in the parentheses. ***, **, and * correspond to the 1,5 and $10 \%$ levels of significance, respectively. The results of the other control variables (dummies for household income, educational status, and occupation) are not presented here for the sake of saving space but are available upon request

$e m s=1$ and $e m s=0$. From the figure, it is somewhat unclear whether the distributions differ across the two groups in a significant manner. Indeed, although the mean of electricity expenditures for $e m s=1$ is greater than that for $e m s=0$, the mean-comparison test shows that there is no significant difference in mean values between the groups. In addition, the Kolmogorov-Smirnov test cannot reject the null hypothesis that the distributions are equal. At first glance, these results seem to suggest that ems is not significantly associated with bill. As we will see, however, the results are an artifact of not controlling for individuals' observed characteristics. 


\subsection{Results}

Table 11 presents the estimation results. We first estimate Eq. (8) without the control variables. As presented in Column (1), the estimated coefficient of ems is positive, which is consistent with Fig. 1e explained above. However, the sign of the coefficient changes from positive to negative after controlling for individuals' observed characteristics (Column (2)). The coefficient becomes even larger in magnitude after further controlling for house types (Column (3)). In both models, the null hypothesis that the coefficient is zero is rejected at the 5\% level. These results are in favor of our hypothesis.

In addition to the statistical significance, the economic significance of the EMS effect may be noteworthy. The point estimates of the coefficient of ems range from -0.03 to -0.06 , corresponding to a decrease in household electricity expenditure by approximately $3-6 \%$. The effect does not seem to be negligible considering that it is a byproduct of EMSs whose original purpose is to help organizations reduce the environmental impacts generated by their activities.

We also find that household electricity expenditure is associated with respondents being male, being older, living with a larger family, and living in an owned detached house. These characteristics are more pronounce for individuals who work in organizations with EMSs than for those who work in organizations without EMSs (see Table 10). This pattern may explain the observation that the mean of electricity expenditures for $e m s=1$ is not significantly different from that for $e m s=0$ as mentioned earlier, despite the effect of ems on electricity expenditures.

\section{Conclusion}

This paper investigated whether an EMS in the workplace promotes energy saving behaviors at home. This argument is supported by data from surveys of individuals in Japan; specifically, we found that the probability that individuals will engage in energy saving practices at home is higher when they work in organizations that implement EMSs than when they work in organizations that do not implement EMSs. We also provide evidence that expenditures on electricity use are lower for individuals who work in organizations with EMSs than for those who work in organizations without EMSs. These results are intriguing because the designers or implementers of EMSs are unlikely to be aware that EMSs play a role in promoting household energy saving.

Nonetheless, our results should be interpreted with caution. First, there are potential drawbacks of self-reported data. There may be a problem in accuracy and exaggeration. The respondents may unconsciously exaggerate their responses due to social desirability. Second, it is possible that having an EMS at work might prime the respondents to overstate behaviors or how low their energy bills are. We note that such effects could lead to the overestimation of an EMS's influence on energy saving practices and electricity bill savings.

Our results have several important implications. First, even if EMSs do not improve the environmental performance of firms or facilities (e.g., Barla 2007; Dahlström et al. 2003; Darnall and Sides 2008), EMSs can be socially beneficial by reducing employees' household energy consumption. This may provide a rationale for the policies that some government authorities have already introduced, such as reduction in the frequency 
Table 12 Estimation results when the "Don't Know" dummy is included

\begin{tabular}{|c|c|c|c|c|}
\hline & (1) & (2) & (3) & (4) \\
\hline & $\begin{array}{l}\operatorname{esp}_{1} \\
(28 \mathrm{C} \geq \text { Summer })\end{array}$ & $\begin{array}{l}e s p_{2} \\
(20 \mathrm{C} \leq \text { Winter })\end{array}$ & $\begin{array}{l}e s p_{3} \\
\text { (Turn off TV) }\end{array}$ & $\begin{array}{l}\operatorname{esp}_{4} \\
\text { (Turn off Light) }\end{array}$ \\
\hline \multirow[t]{2}{*}{ ems } & $0.308 * * *$ & $0.540 * * *$ & $0.309 * * *$ & $0.313 * * *$ \\
\hline & $(0.088)$ & $(0.0956)$ & $(0.071)$ & $(0.063)$ \\
\hline \multirow{2}{*}{$\begin{array}{l}e m s \_d k \text { : Don't know whether } \\
\text { EMS is adopted }\end{array}$} & -0.118 & -0.160 & $-0.137 * *$ & $-0.099 *$ \\
\hline & $(0.086)$ & $(0.121)$ & $(0.069)$ & $(0.059)$ \\
\hline \multicolumn{5}{|l|}{ Average partial effect of ems on } \\
\hline \multirow[t]{2}{*}{$\operatorname{Pr}($ Never $)$} & $-0.057 * * *$ & $-0.130 * * *$ & $-0.078 * * *$ & $-0.078 * * *$ \\
\hline & $(0.017)$ & $(0.022)$ & $(0.019)$ & $(0.016)$ \\
\hline \multirow[t]{2}{*}{$\operatorname{Pr}($ Rarely) } & $-0.038 * * *$ & $-0.044 * * *$ & $-0.034 * * *$ & $-0.037 * * *$ \\
\hline & $(0.011)$ & $(0.008)$ & $(0.008)$ & $(0.007)$ \\
\hline \multirow[t]{2}{*}{$\operatorname{Pr}$ (Occasionally) } & $-0.010 * * *$ & $0.015 * * *$ & $-0.004 * * *$ & 0.001 \\
\hline & $(0.003)$ & $(0.003)$ & $(0.001)$ & $(0.001)$ \\
\hline \multirow[t]{2}{*}{$\operatorname{Pr}$ (Fairly often) } & $0.105^{* * *}$ & $0.159 * * *$ & $0.116^{* * *}$ & $0.114 * * *$ \\
\hline & $(0.03)$ & $(0.027)$ & $(0.027)$ & $(0.023)$ \\
\hline Obs & 1435 & 923 & 1641 & 1723 \\
\hline
\end{tabular}

Standard errors clustered by prefecture are presented in the parentheses. $* * *, * *$, and * correspond to the 1, 5 and $10 \%$ levels of significance, respectively. The same control variables as in Table 3 are included in each model. The results for control variables and the results for the average partial effects on $\operatorname{Pr}(\operatorname{Rarely})$ and $\operatorname{Pr}$ (Occasionally) are not presented here for the sake of saving space but are available upon request

of inspections and provision of subsidies for organizations that implement (certified) EMSs.

Second, the effect of EMSs may be even larger than our results indicate due to green supply chain management. According to Arimura et al. (2011), facilities with certified EMSs are more likely to require that their suppliers undertake specific environmental practices, one of which is often EMS implementation. Our results, combined with those of Arimura et al. (2011), suggest that when an EMS is implemented by a downstream firm, upstream firms tend to start implementing EMSs, which in turn makes it more likely that employees in the upstream firms engage in energy saving activities. Thus, EMSs may have a multiplier effect on household energy saving behaviors.

Lastly, recommendations are provided for future research directions. One direction is to examine a wider variety of energy saving practices than those this study addresses. Another and more fruitful direction may be to conduct a cross-country study and thereby examine whether findings in this study can be generalized to countries other than Japan.

\section{Appendix Robustness Check: Treatment of "Don't Know" Responses}

The results we presented were obtained through an equal treatment of the respondents who answered "no" and those who answered "don't know" to the question "(h)as the organization that you work for implemented an environment management system?." To examine the 
robustness of our findings to this assumption, we now include $e m s_{-} d k$ in the models and thereby allow for the possibility that "don't know" is not equivalent to "no."

As presented in Table 12, for all models, the inclusion of ems_dk does not change the pattern of the estimated coefficients on ems; their sign and significance remain the same as before. Although the average partial effects on the probability of "fairly often" ("never") become somewhat smaller in magnitude, they are still larger than ten (five) percentage points when significant. According to these estimates, our main findings seem to be robust to the treatment of "don't know" responses. ${ }^{10}$

The results also show that "no" and "don't know" responses are not necessarily equivalent; when we examine the TV practice $\left(e s p_{3}\right)$ and the light practice $\left(e s p_{4}\right)$, the coefficients on $e m s \_d k$ are found to be statistically significant at the 5\% level. There are two possible interpretations for these results. First, if most of those responding with "don't know" work for organizations that do not implement an EMS, then the results may be interpreted to indicate that they tend to care less about energy saving practices than those who answered "no" (and hence are less engaged in the practices). In other words,ems_dk $=1$ may capture individuals who are unconcerned about energy saving practices. Second, if most of those responding with "don't know" work for organizations that implement an EMS, the results may also imply that EMSs unnoticed by employees do not influence their energy saving behaviors; in other words, employees should be well informed about EMSs (as is required by ISO 14001) to promote their energy saving behavior.

Acknowledgements We appreciate the financial support from JSPS. Kakenhi Grant number 15H03352. Mari Sakudo is grateful for the JSPS financial grant 17K03748 and the support from JCER. Toshi Arimura is grateful for the Environment Research and Technology Development Fund (JPMEERF20202008) of the Environmental Restoration and Conservation Agency. We are thankful for the helpful comments from Koki Oikawa and seminar participants at Waseda University, Tsukuba University, National Institute for Environmental Studies, Development Bank of Japan, and Institute of Statistical Research Resources for the Future.

Open Access This article is licensed under a Creative Commons Attribution 4.0 International License, which permits use, sharing, adaptation, distribution and reproduction in any medium or format, as long as you give appropriate credit to the original author(s) and the source, provide a link to the Creative Commons licence, and indicate if changes were made. The images or other third party material in this article are included in the article's Creative Commons licence, unless indicated otherwise in a credit line to the material. If material is not included in the article's Creative Commons licence and your intended use is not permitted by statutory regulation or exceeds the permitted use, you will need to obtain permission directly from the copyright holder. To view a copy of this licence, visit http://creativecommons.org/licenses/by/4.0/.

\footnotetext{
${ }^{10}$ For the models presented in Table 12 , we conducted endogeneity tests in a manner similar to that described in the main text. Specifically, we first extend Eq. (2) by including ems_dk $: e s p_{j}^{*}=\alpha_{1 j} \cdot e m s+\alpha_{2 j} \cdot e m s \_d k+\boldsymbol{x} \boldsymbol{\beta}_{j}+\rho_{1 j} \cdot \omega_{1 j}+\rho_{2 j} \cdot \omega_{2 j}+v_{j}$, where $\omega_{1 j}\left(\omega_{2 j}\right)$ captures a set of unobserved factors that are uncorrelated with $\boldsymbol{x}$ but correlated with ems (ems_dk). We also modify Eq. (3) as follows:ems $=g_{1}\left(\boldsymbol{x} \gamma_{1 j}+z \delta_{1 j}\right)+\omega_{1 j}$ and $e m s \_d k=g_{2}\left(\boldsymbol{x} \gamma_{2 j}+z \delta_{2 j}\right)+\omega_{2 j}$. For $g_{k}(\bullet),(k=1,2)$, we choose a multinomial logit form. Then, these equations become a multinomial logit model where the base category is "no." Given this setup, we use the following two-stage procedure. In the first stage, we estimate the multinomial logit model using maximum likelihood and compute the residuals $\widehat{\omega}_{1 j}=e m s-g_{1}\left(x \widehat{\gamma}_{1 j}+z \widehat{\delta}_{1 j}\right)$ and $\widehat{\omega}_{2 j}=e m s_{-} d k-g_{2}\left(x \hat{\gamma}_{2 j}+z \hat{\delta}_{2 j}\right)$. In the second stage, we estimate the ordered probit model by substituting $\widehat{\omega}_{k j}$ into $\omega_{k j}(k=1,2)$. The joint null hypothesis that $\rho_{1 j}=\rho_{2 j}=0$ (i.e., the exogeneity of ems and ems_dk) can be tested by using a Wald test. In almost all models, we obtained results in favor of the exogeneity of ems(and ems_dk).
} 


\section{References}

Abrahamse W, Steg L, Vlek C, Rothengatter T (2005) A review of intervention studies aimed at household energy conservation. J Environ Psychol 25(3):273-291

Altonji JG, Elder TE, Taber CR (2005) Selection on observed and unobserved variables: assessing the effectiveness of catholic schools. J Polit Econ 113(1):151-184

Arimura TH, Hibiki A, Katayama H (2008) Is a voluntary approach an effective environmental policy instrument?: A case for environmental management systems. J Environ Econ Manag 55(3):281-295

Arimura TH, Darnall N, Katayama H (2011) Is ISO 14001 a gateway to more advanced voluntary action? The case of green supply chain management. J Environ Econ Manag 61(2):170-182

Barla P (2007) ISO 14001 certification and environmental performance in Quebec's pulp and paper industry. J Environ Econ Manag 53(3):291-306

Brouwer MAC, van Koppen CSA (Kris) (2008) The soul of the machine: continual improvement in ISO 14001. J Clean Prod 16(4):450-457

Cable DM, Judge TA (1996) Person-organization fit, job choice decisions, and organizational entry. Organ Behav Hum Decis Process 67(3):294-311

Coglianese C, Nash J (2001) Environmental management system and the new policy agenda. In: Coglianese C, Nash J (eds) Regulation from the inside: can environmental management system achieve policy goals, resources for the Future Press, Washington, DC.

European Commission (2017) http://ec.europa.eu/environment/emas/emas_registrations/statistics_graphs_ en.htm accessed in March 2018.

Energy Conservation Center, Japan (2012) https://www.eccj.or.jp/dict/pdf/dict_all.pdf. Accessed in March 2018.

Daddi T, Magistrelli M, Frey M, Iraldo F (2011) Do environmental management systems improve environmental performance? Empirical evidence from Italian companies. Environ Dev Sustain 13(5):845-862

Dahlström K, Howes C, Leinster P, Skea J (2003) Environmental management systems and company performance: assessing the case for extending risk-based regulation. Eur Environ 13(4):187-203

Darnall N, Sides S (2008) Assessing the performance of voluntary environmental programs: does certification matter? Policy Stud J 36(1):95-117

Dasgupta S, Hettige H, Wheeler D (2000) What improves environmental compliance? Evidence from Mexican industry. J Environ Econ Manag 39:39-66

Dollinger SJ, O’Donnell JP, Staley AA (1984) Lightning-strike disaster: effects on children's fears and worries. J Consult Clin Psychol 52(6):1028-1038

Dzioubinski O, Chipman R (1999) Trends in consumption and production: Household energy consumption. Discussion paper No. 6, United Nations, Department of Economic and Social Affairs.

Gavrilets S, Richerson PJ (2017) Collective action and the evolution of social norm internalization. Proc Natl Acad Sci USA (PNAS) 114(23):6068-6073

Hausman JA (1978) Specification tests in econometrics. Econometrica 46(6):1251-1271

Hillary R, Gelber M, Biondi V, Tamborra M (1998) An assessment of the implementation status of council regulation (No 1836/93) eco-management and audit scheme (EMAS) in the European Union Member States (AIMS-EMAS), EU Commission Working Document.

Iraldo F, Testa F, Frey M (2009) Is an environmental management system able to influence environmental and competitive performance? The case of the eco-management and audit scheme (EMAS) in the European Union. J Clean Prod 17(16):1444-1452

ISO (2003) The ISO survey of ISO 9001: 2000 and ISO 14001 certificates-2003.https://www.iso.org/files/ live/sites/isoorg/files/archive/pdf/en/survey2003.pdf. Accessed in April 2018.

ISO (2016) ISO Survey 2016. https://www.iso.org/the-iso-survey.html. Accessed in March 2018.

Jabbour CJC (2013) Environmental training in organizations: from a literature review to a framework for future research. Resour Conserv Recycl 74:144-155

Klimkiewicz K, Oltra V (2017) Does CSR enhance employer attractiveness? The role of millennial job seekers' attitudes. Corp Soc Responsib Environ Manag 24(5):449-463

Lewbel A (2012) Using heteroscedasticity to identify and estimate mismeasured and endogenous regressor models. J Bus Econ Stat 30(1):67-80

Lewbel A (2018) Identification and estimation using heteroscedasticity without instruments: The binary endogenous regressor case. Econ Lett 165(C):10-12.

Lim S, Prakash A (2014) Voluntary regulations and innovation: The case of ISO 14001. Public Adm Rev 74:233-244

Melillo JM, Richmond TC, Yohe GW (eds) (2014) Highlights of Climate Change Impacts in the United States: The Third National Climate Assessment, U.S. Global Change Research Program, the U.S. Government Printing Office. 
Nakamura M, Takahashi T, Vertinsky I (2001) Why Japanese firms choose to certify: a study of managerial responses to environmental issues. J Environ Econ Manag 42(1):23-52

Nishitani K (2011) An empirical analysis of the effects on firms' economic performance of implementing environmental management systems. Environ Resource Econ 48(4):569-586

Pan JN (2003) A comparative study on motivation for and experience with ISO 9000 and ISO 14000 certification among Far Eastern countries. Ind Manag Data Syst 103(8):564-578

Poksinska B, Dahlgaard J, Eklund J (2003) Implementing ISO 14000 in Sweden: motives, benefits and comparisons with ISO 9000. Int J Qual Reliability Manage 20(5):585-606

Potoski M, Prakash A (2005) Covenants with weak swords: ISO 14001 and facilities' environmental performance. J Policy Anal Manage 24(4):745-769.

Prakash A, Potoski M (2006) The voluntary environmentalists: Green clubs, ISO 14001, and voluntary environmental regulations. Cambridge University Press, Cambridge.

Rennings K, Ziegler A, Ankele K, Hoffmann E (2006) The influence of different characteristics of the EU environmental management and auditing scheme on technical environmental innovations and economic performance. Ecol Econ 57(1):45-59

Rondinelli D, Vastag G (2000) Panacea, common sense, or just a label?: The value of ISO 14001 environmental management systems. Eur Manag J 18(5):499-510

Russo MV (2002) Institutional change and theories of organizational strategy: ISO14001 and toxic emissions in the electronics industry. Acad Manag Proc 1:A1-A6

Schylander E, Martinuzzi A (2007) ISO 14001—experiences, effects and future challenges; A national study in Austria. Bus Strateg Environ 16(2):133-147

Siero S, Boon M, Kok G, Siero FW (1989) Modification of driving behavior in a large transport organization: a field experiment. J Appl Psychol 74(3):417-423

Tan LP (2005) Implementing ISO 14001: is it beneficial for firms in newly industrialized Malaysia? J Clean Prod 13(4):397-404

Tari JJ, Molina-Azorin JF, Heras I (2012) Benefits of the ISO 9001 and ISO 14001 standards: a literature review. J Ind Eng Manage 5(2):297-322

Terza JV, Basu A, Rathouz PJ (2008) Two-stage residual inclusion estimation: addressing endogeneity in health econometric modeling. J Health Econ 27(3):531-543

The Commonwealth of Australia (2017) http://www.environment.gov.au/node/20494. Accessed in October 2017.

Thøgersen J, Ölander F (2003) Spillover of environment-friendly consumer behaviour. J Environ Psychol 23(3):225-236

United States Environmental Protection Agency (2014) http://www.epa.gov/ems/. Accessed in December 2014.

Wagner M (2007) On the relationship between environmental management, environmental innovation and patenting: Evidence from German manufacturing firms. Res Policy 36(10):1587-1602

Wagner M (2008) Empirical influence of environmental management on innovation: Evidence from Europe. Ecol Econ 66(2-3):392-402

Wooldridge JM (2010) Econometric analysis of cross section and panel data. The MIT press, Cambridge, Massachusetts, London, The second edition

Zutshi A, Sohal AS (2004) Adoption and maintenance of environmental management systems: critical success factors. Manage Environ Qual Int J 15(4):399-419

Publisher's Note Springer Nature remains neutral with regard to jurisdictional claims in published maps and institutional affiliations. 